\title{
Redefining genera of cereal pathogens: Oculimacula, Rhynchosporium and Spermospora
}

\author{
P.W. Crous ${ }^{1,2,3^{*}}$, U. Braun ${ }^{4}$, B.A. McDonald ${ }^{5}$, C.L. Lennox ${ }^{6}$, J. Edwards ${ }^{7,8}$, R.C. Mann ${ }^{7}$, A. Zaveri ${ }^{8}$, C.C. Linde ${ }^{9}$, P.S. Dyer ${ }^{10}$, J.Z. Groenewald ${ }^{1}$
}

\begin{abstract}
${ }^{1}$ Westerdijk Fungal Biodiversity Institute, Uppsalalaan 8, 3584 CT, Utrecht, The Netherlands
${ }^{2}$ Wageningen University and Research Centre (WUR), Laboratory of Phytopathology, Droevendaalsesteeg 1, 6708 PB Wageningen, The Netherlands ${ }^{3}$ Microbiology, Department of Biology, Utrecht University, Padualaan 8, $3584 \mathrm{CH}$ Utrecht, The Netherlands

${ }^{4}$ Martin-Luther-Universität, Institut für Biologie, Bereich Geobotanik und Botanischer Garten, Herbarium, Neuwerk 21, 06099 Halle (Saale), Germany ${ }^{5}$ ETH Zürich, Plant Pathology, Institute of Integrative Biology (IBZ), Universitätstrasse 2, LFW B16, 8092 Zürich, Switzerland

${ }^{6}$ Department of Plant Pathology, Stellenbosch University, Stellenbosch 7600, South Africa

${ }^{7}$ Agriculture Victoria Research, Department of Jobs, Precincts and Regions, AgriBio Centre, 5 Ring Road, LaTrobe University, Bundoora, Victoria 3083 Australia

${ }^{8}$ School of Applied Systems Biology, LaTrobe University, Bundoora, Victoria 3083 Australia

${ }^{9}$ Ecology and Evolution, Research School of Biology, College of Science, The Australian National University, 46 Sullivans Creek Road, Acton, ACT 2600, Australia

${ }^{10}$ School of Life Sciences, University of Nottingham, Life Sciences Building, University Park, Nottingham NG7 2RD, UK
\end{abstract}

*Corresponding author: p.crous@wi.knaw.nl

\section{Key words:}

Eyespot disease

Helotiales

leaf blotch

new taxa

systematics

\begin{abstract}
The taxonomy of Oculimacula, Rhynchosporium and Spermospora is re-evaluated, along with that of phylogenetically related genera. Isolates are identified using comparisons of DNA sequences of the internal transcribed spacer ribosomal RNA locus (ITS), partial translation elongation factor 1-alpha (tef1), actin (act), DNA-directed RNA polymerase II largest (rpb1) and second largest subunit (rpb2) genes, and the nuclear ribosomal large subunit (LSU), combined with their morphological characteristics. Oculimacula is restricted to two species, $O$. acuformis and $O$. yallundae, with $O$. aestiva placed in Cyphellophora, and $O$. anguioides accommodated in a new genus, Helgardiomyces. Rhynchosporium s. str. is restricted to species with 1-septate conidia and hooked apical beaks, while Rhynchobrunnera is introduced for species with 1-3-septate, straight conidia, lacking any apical beak. Rhynchosporium graminicola is proposed to replace the name $R$. commune applied to the barley scald pathogen based on nomenclatural priority. Spermospora is shown to be paraphyletic, representing Spermospora (type: S. subulata), with three new species, S. arrhenatheri, S. Ioliiphila and S. zeae, and Neospermospora gen. nov. (type: N. avenae). Ypsilina (type: Y. graminea), is shown to be monophyletic, but appears to be of minor importance on cereals. Finally, Vanderaaea gen. nov. (type: V. ammophilae), is introduced as a new coelomycetous fungus occurring on dead leaves of Ammophila arenaria.
\end{abstract}

Citation: Crous PW, Braun U, McDonald BA, Lennox CL, Edwards J, Mann RC, Zaveri A, Linde CC, Dyer PS, Groenewald JZ (2020). Redefining genera of cereal pathogens: Oculimacula, Rhynchosporium and Spermospora. Fungal Systematics and Evolution 7: 67-98. doi: 10.3114/fuse.2021.07.04 Received: 10 September 2020; Accepted: 1 December 2020; Effectively published online: 7 December 2020

Corresponding editor: Lei Cai

\section{INTRODUCTION}

Cereal crops are mainly cultivated for their edible grain. These crops are of enormous economic and social importance globally (McKevith 2004), but are susceptible to a wide array of foliar pathogens. Many of the most important cereal crop pathogens are fungi that cause leaf spot diseases (Dean et al. 2012, Doehlemann et al. 2017). These diseases inhibit grain filling by reducing photosynthesis and increasing plant respiration, leading to lower grain yields.

Several fungal genera pathogenic to cereals have recently been revised. These include Cercospora (grey leaf spot in maize, caused by C. zeina; Groenewald et al. 2013), Exserohilum (northern corn leaf blight of maize and sorghum caused by E. turcicum;
Hernández-Restrepo et al. 2018), Pyrenophora (tan spot of wheat caused by $P$. tritici-repentis, and net blotch of barley caused by $P$. teres; Marin-Felix et al. 2019a), Pyricularia rice blast caused by Py. oryzae (Klaubauf et al. 2014) and wheat blast caused by $P y$. oryzae Triticum pathotype (= Py. graminis-tritici), Zymoseptoria (Septoria tritici blotch caused by Z. tritici; Stukenbrock et al. 2012), Parastagonospora (Septoria nodorum blotch caused by $P a$. nodorum; Quaedvlieg et al. 2013), Bipolaris (spot blotch caused by B. sorokiniana; Manamgoda et al. 2014), Curvularia (leaf spots on a range of grasses and cereals; Manamgoda et al. 2012), and Ramularia (Ramularia leaf spot of barley caused by $R a$. collocygni; Videira et al. 2016), to name but a few.

Despite these numerous morphological studies coupled with DNA-based sequence analyses leading to taxonomic 
revisions, the generic boundaries of many other foliar cereal pathogens remain insufficiently resolved. In many cases, existing pathogenic genera include a range of species that in the past were defined based only on their disease symptomatology, morphological similarity and/or host range. These genera are ripe for critical phylogenetic and morphological re-evaluation using modern methods. The aim of the present study was to recircumscribe a complex of closely related fungal genera, namely Rhynchosporium (leaf blotch or scald of cereal and grass hosts), Oculimacula (eyespot disease of wheat), Septogloeum (leaf spots on strawberries, elms, mulberries and hazel), Spermospora (red leather leaf disease of oats) and Ypsilina (isolated from diverse substrates, including wheat).

\section{MATERIALS AND METHODS}

\section{Isolates}

Reference strains of the studied fungi are maintained in the following collections: the CBS culture collection (CBS) of the Westerdijk Fungal Biodiversity Institute (WI), Utrecht, the Netherlands, the Department of Plant Pathology, Institute of Integrative Biology, ETH, Zurich, Switzerland, Victorian Plant Pathogen Herbarium, VPRI, Bundoora, Australia, and the School of Life Sciences, University of Nottingham, UK. Colonies were subcultured on $2 \%$ potato dextrose agar (PDA), oatmeal agar (OA), $2 \%$ malt extract agar (MEA), and synthetic nutrient-poor agar (SNA), and incubated at $25{ }^{\circ} \mathrm{C}$ under continuous near-ultraviolet light to promote sporulation (for recipes see Crous et al. 2019b).

\section{DNA extraction, amplification (PCR) and phylogeny}

Fungal mycelium (Table 1) was scraped from the agar surface of cultures with a sterile scalpel and the genomic DNA was isolated using the Wizard ${ }^{\circledR}$ Genomic DNA Purification Kit (Promega Corporation, WI, USA) following the manufacturers' protocols. Six loci were amplified following previously published protocols. First, the $28 \mathrm{~S}$ nrRNA gene (LSU) and internal transcribed spacer regions with intervening $5.8 \mathrm{~S}$ nrRNA gene (ITS) of the nrDNA operon were sequenced for all the isolates included in this study (for amplification conditions, see Fan et al. 2018). Amplification profiles of the partial DNAdirected RNA polymerase II second largest subunit gene (rpb2) and the partial translation elongation factor 1-alpha gene (tef1) followed Braun et al. (2018), while those of the partial actin gene (act) followed Videira et al. (2016) and of the partial DNA-directed RNA polymerase II largest subunit gene (rpb1) followed Pärtel et al. (2017). The resulting fragments were sequenced in both directions using the respective PCR primers and the BigDye Terminator Cycle Sequencing Kit v. 3.1 (Applied Biosystems Life Technologies, Carlsbad, CA, USA). DNA sequencing amplicons were purified through Sephadex G-50 Superfine columns (Sigma-Aldrich, St. Louis, MO) in MultiScreen HV plates (Millipore, Billerica, MA). Purified sequence reactions were analysed on an Applied Biosystems 3730xI DNA Analyzer (Life Technologies, Carlsbad, CA, USA). The DNA sequences were analysed and consensus sequences were computed using Geneious v. 11.1 .5 (Kearse et al. 2012; https://www.geneious.com). The two Australian isolates of Spermospora avenae had a different extraction protocol, followed by Illumina sequencing (see Zaveri et al. 2020).
The sequences for each locus were subjected to megablast searches (Zhang et al. 2000) to identify similar sequences in the NCBI GenBank nucleotide database. Sequences of the individual loci (ITS, LSU, act, tef1, rpb1, rpb2) were aligned using MAFFT v. 7 (http://mafft.cbrc.jp/alignment/server/index.html, Katoh \& Standley 2013), and the alignments were then manually edited in MEGA v. 7.0.21. Sequence Matrix v. 1.8 (http://www.ggvaidya. com/taxondna/) was used to concatenate the individual loci in various combinations. Phylogenetic trees were generated using Bayesian analyses (BA) (Supplementary Figs S1-S6, overview LSU phylogeny Fig. 1) performed with MrBayes v. 3.2.7 (Ronquist et al. 2012) as explained in Braun et al. (2018). The data matrices of different combinations of individual loci included: 1) all six loci containing all sequences from Figs S1-S6 (Fig. S7; ITS/LSU/ $a c t / r p b 1 / r p b 2 / t e f 1), 2$ ) an alignment of the four loci which represent a more complete dataset (Fig. S8; ITS/LSU/act/tef1), 3) an alignment of the two loci for which the least number of sequences were available (Fig. S9; $r p b 1 / r p b 2$ ) and 4) a reduced set of the 6-gene alignment derived from Fig. S7 (presented here as Fig. 2). Tree and character statistics for the different analyses are listed in Table 2 . All resulting trees were printed with Geneious v. 11.1.5 and the layout of the trees was done in Adobe Illustrator v. CC 2017. Sequences derived in this study were deposited in GenBank (Table 1), the alignment in TreeBASE (www.treebase.org; study number 27325), and taxonomic novelties in MycoBank (www.MycoBank.org; Crous et al. 2004).

\section{Morphology}

Slide preparations were mounted in lactic acid or Shear's mounting fluid, from colonies sporulating on SNA. Observations were made with a Nikon SMZ25 dissection-microscope, and with a Zeiss Axio Imager 2 light microscope using differential interference contrast (DIC) illumination and images recorded on a Nikon DS-Ri2 camera with associated software. Colony characters and pigment production were noted after $2-4$ wk of growth on MEA, PDA and OA (Crous et al. 2019b) incubated at $25^{\circ} \mathrm{C}$.

\section{RESULTS}

\section{Phylogeny}

In the overview LSU phylogeny (Fig. 1, part 2), two cultures (CBS 497.80, CBS 886.68) were found to cluster outside of Ploettnerulaceae (Helotiales, Leotiomycetes). The ex-isotype culture (CBS 497.80) of Pseudocercosporella aestiva clustered in Cyphellophora (Cyphellophoraceae, Chaetothyriales, Eurotiomycetes) and therefore a new combination in this genus is introduced for it below. A culture deposited in the CBS culture collection as Spermospora avenae (CBS 886.68) was found to be distantly related to Neoacrodontiella eucalypti (Acarosporaceae, Acarosporales, Lecanoromycetes) with no high similarity hits found in GenBank and therefore a new genus and species, Vanderaaea ammophilae, is introduced for it below.

Four-gene (Fig. S8) and 2-gene (Fig. S9) analyses were performed to confirm that the lack of $r p b 1$ and $r p b 2$ sequences for several samples is not influencing the tree topology in the 6 -gene phylogenies (Figs 2, S7). The main difference in overall topology between the two 6-gene phylogenies (Figs 2, S7) is the placement of the Helgardiomyces and Ypsilina clades, with the Ypsilina clade positioned in an unresolved basal polytomy in Fig. 
S7 whereas it forms the most basal resolved lineage in Fig. 2. The 2-gene (Fig. S9) and 4-gene (Fig. S8) phylogenies resolved the same general lineages as the 6-gene phylogenies (Figs 2 , S7) but differed mainly in the order of divergence of some clades. For example, Spermospora was consistently the sister lineage to Oculimacula whereas genera such as Helgardiomyces and Ypsilina had alternative placements in the different tree topologies. The 2-gene phylogeny (Fig. S9) is overall more similar to the 6-gene phylogenies (Figs 2, S7), with the exception of the placement of Helgardiomyces anguioides.

Based on these phylogenetic trees, several taxonomic decisions were made and the phylogenetic relationships of individual groups are discussed under the Notes of respective taxa in the Taxonomy section below.

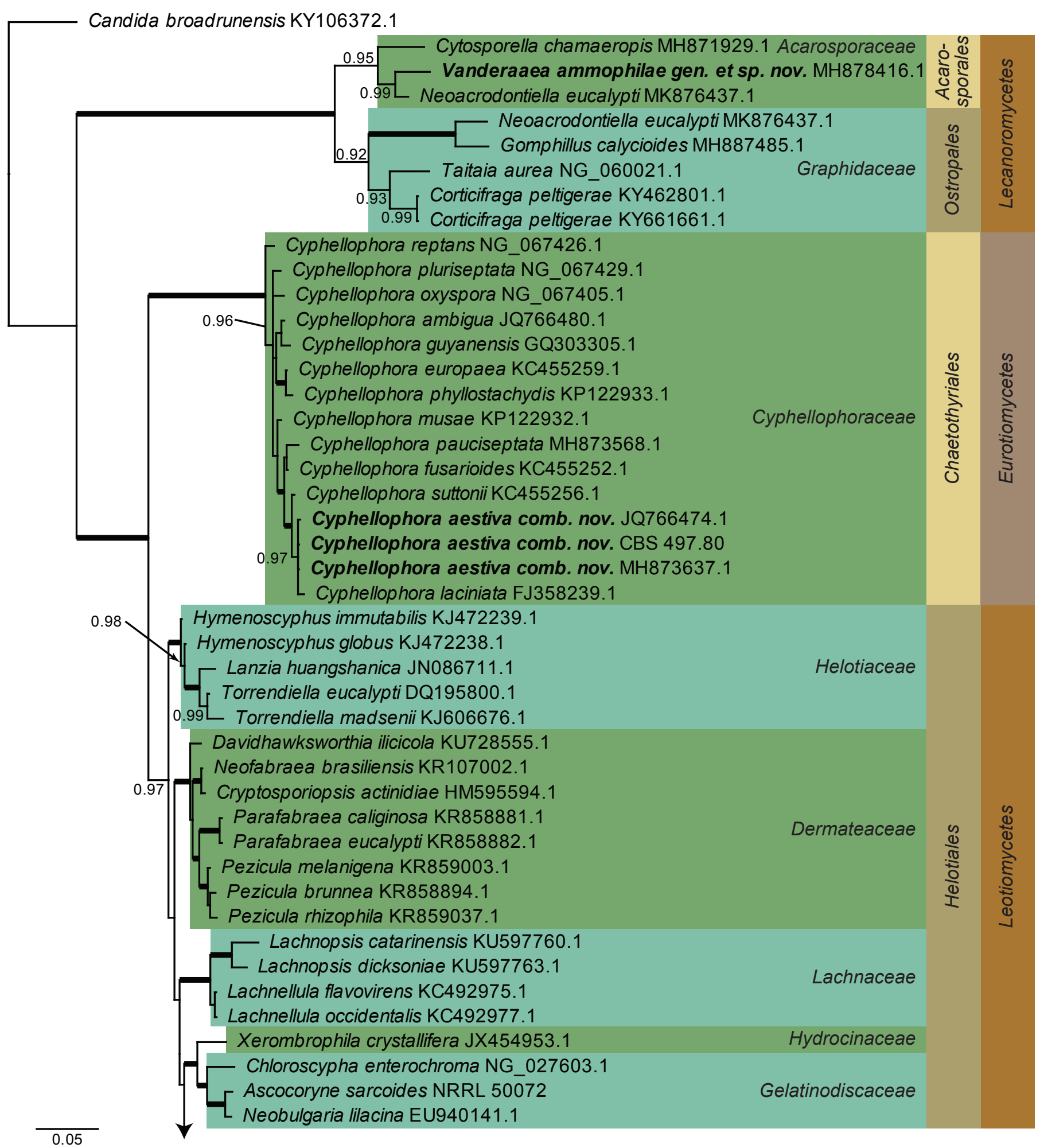

Fig. 1. Consensus phylogram ( $50 \%$ majority rule) resulting from a Bayesian analysis of the LSU sequence alignment. Bayesian posterior probabilities (PP) $>0.89$ are shown at the nodes and thickened lines represent nodes with PP $=1.00$. The scale bar represents the expected changes per site. Families, orders and classes are indicated with coloured blocks to the right of the tree. GenBank accession and/or culture collection numbers are indicated behind the species names. The tree was rooted to Candida broadrunensis (GenBank KY106372.1) and the taxonomic novelties described in this study are indicated in bold face. 
$\uparrow$ [ Collembolispora aristata NG_042760.1

Spermospora arrhenatheri sp. nov. MH870856.1

Spermospora ciliata CBS 135.38

Spermospora zeae sp. nov. CBS 306.79

Spermospora ciliata CBS 285.69

Spermospora ciliata CBS 287.69

Spermospora zeae sp. nov. CBS 316.68

Spermospora loliiphila sp. nov. CBS 286.69

Helgardiomyces anguioides gen. et comb. nov. MH873055.1

Ypsilina graminea MH874529.1

Ypsilina graminea CBS 691.92

Ypsilina graminea CBS 895.72

Ypsilina graminea CBS 692.92

Neospermospora sp. CBS 388.64

Neospermospora avenae gen. et comb. nov. VPRI 42798

Neospermospora avenae gen. et comb. nov. VPRI 42892a

Neospermospora avenae gen. et comb. nov. CBS 227.38

Rhynchobrunnera orthospora comb. nov. CBS 146767

Rhynchobrunnera orthospora comb. nov. CPC 39392

Rhynchobrunnera lolii gen. et comb. nov. KU844336.1

Rhynchobrunnera orthospora comb. nov. CBS 698.79

Rhynchobrunnera orthospora comb. nov. KU844335.1

Oculimacula acuformis CBS 114730

Oculimacula acuformis CBS 495.80

Oculimacula yallundae MH867704.1

Oculimacula yallundae CBS 110665

0.98 Oculimacula yallundae CBS 128.31

Oculimacula yallundae CBS 494.80

Oculimacula yallundae MH866603.1

Cadophora malorum MH866768.1

Cadophora malorum MF494620.1

0.95 Cadophora fastigiata MH871243.1

Cadophora luteo-olivacea MH867586.1

Mycochaetophora gentianae AB496937.1

L Mycochaetophora gentianae AB469686.2

- Cadophora microspora MK591966.1

Rhexocercosporidium carotae AB469688.2

L Rhexocercosporidium carotae KP671743.1

Rhynchosporium agropyri CBS 146769

Rhynchosporium agropyri CBS 146770

Rhynchosporium agropyri CBS 146762

Rhynchosporium graminicola CBS 135932

Rhynchosporium graminicola CBS 110528

Rhynchosporium graminicola CBS 397.61

Rhynchosporium agropyri KU844334.1

Rhynchosporium graminicola KU844332.1

Rhynchosporium graminicola CBS 146763

Rhynchosporium graminicola CBS 146765

Rhynchosporium graminicola CBS 146764

Rhynchosporium graminicola CBS 146766

Rhynchosporium graminicola CBS 146761

Rhynchosporium secalis KU844333.1

0.95. Rhynchosporium secalis CBS 146771

Rhynchosporium secalis CBS 146772

Fig. 1. (Continued). 
Ascocoryne sarcoides NRRL 50072

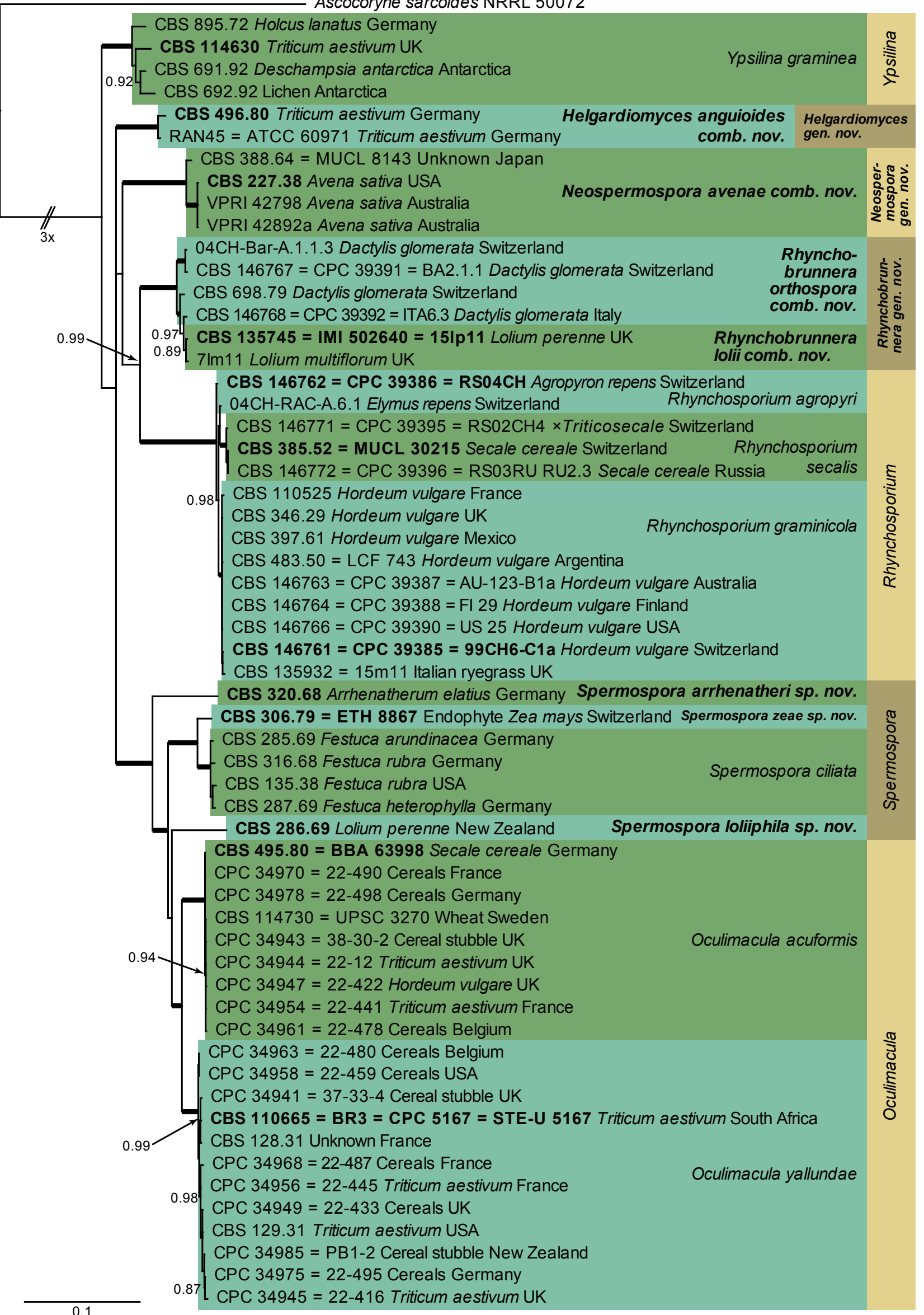

Fig. 2. Consensus phylogram ( $50 \%$ majority rule) resulting from a Bayesian analysis of the reduced set 6-gene (ITS, LSU, act, tef1, rpb1, rpb2) sequence alignment. Bayesian posterior probabilities (PP) $>0.85$ are shown at the nodes and thickened lines represent nodes with PP $=1.00$. The scale bar represents the expected changes per site. Species and genera are indicated with coloured blocks to the right of the tree. Culture collection numbers are followed by the host and country of origin where known. The tree was rooted to Ascocoryne sarcoides (culture NRRL 50072) and the taxonomic novelties described in this study and cultures with a type status are indicated in bold face. 

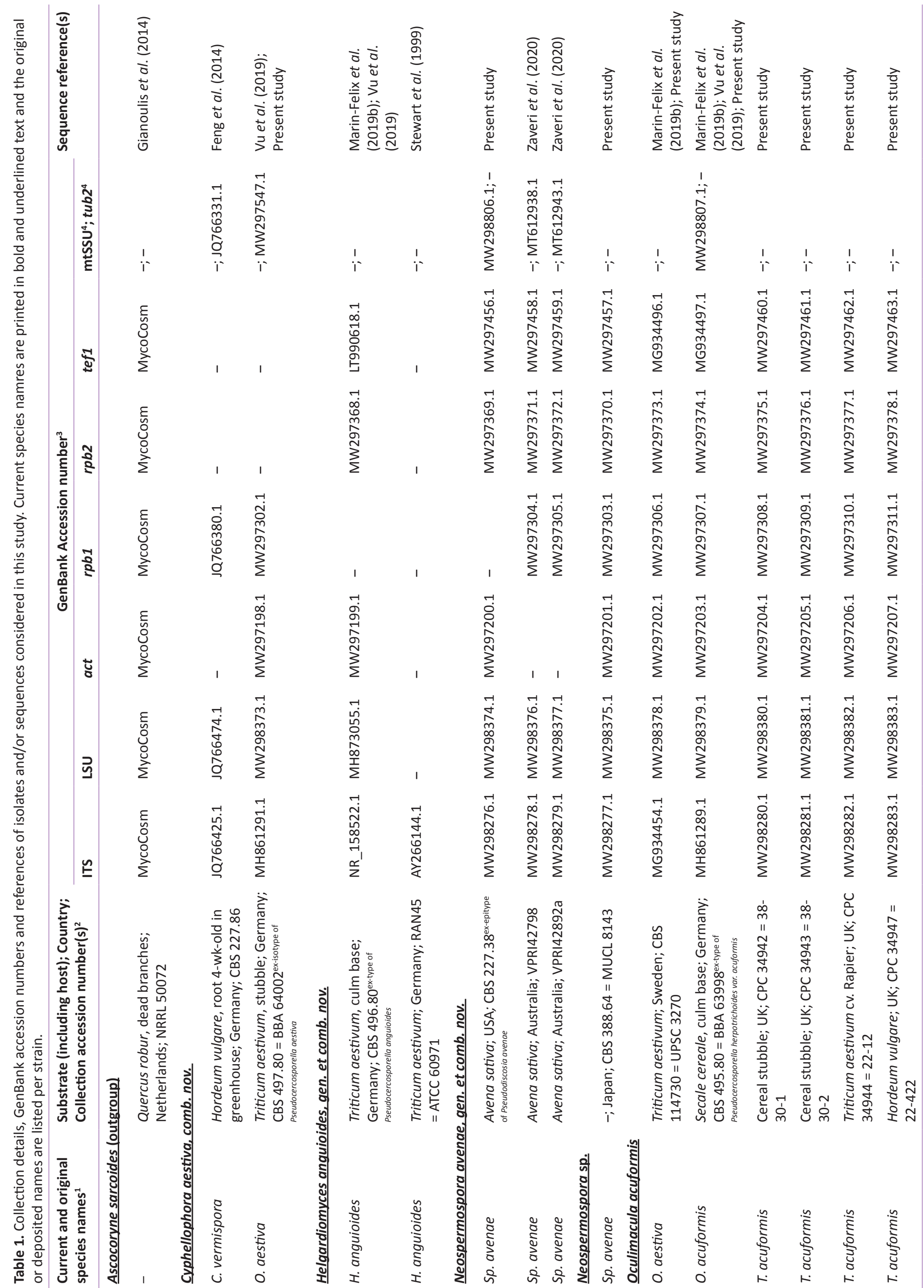


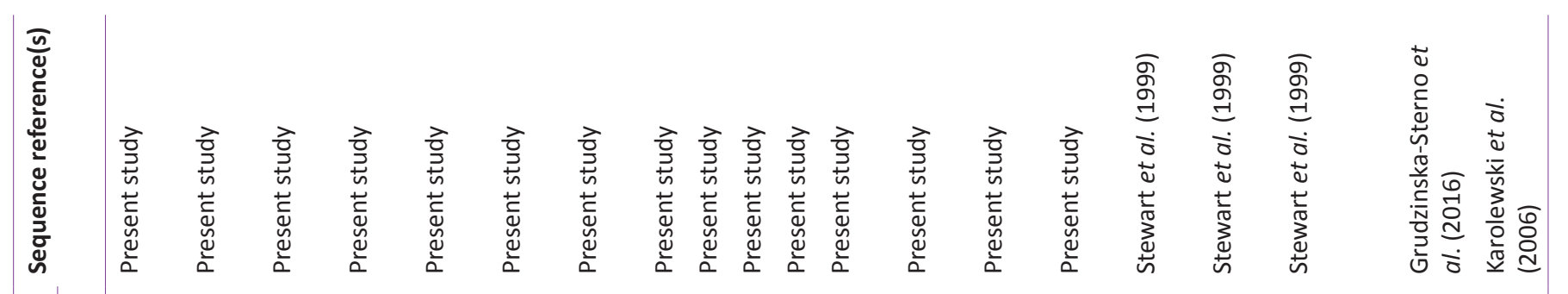

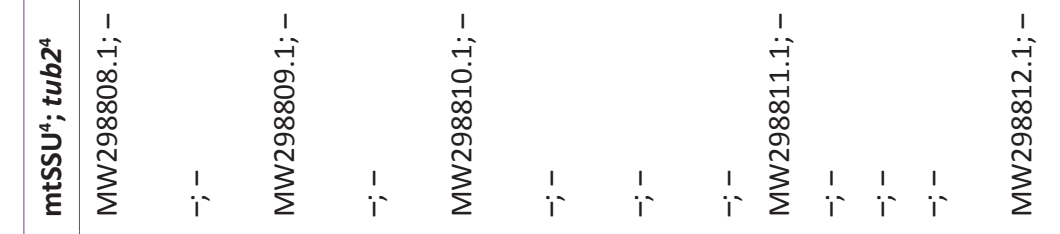

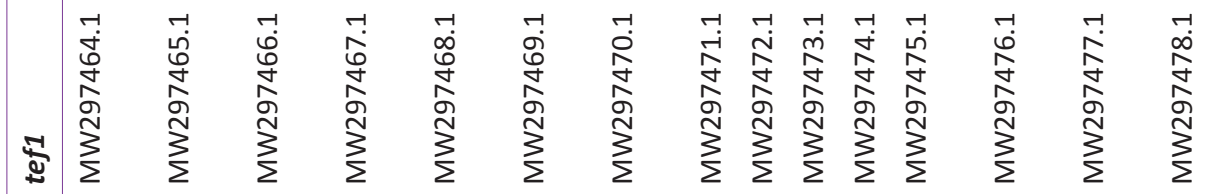

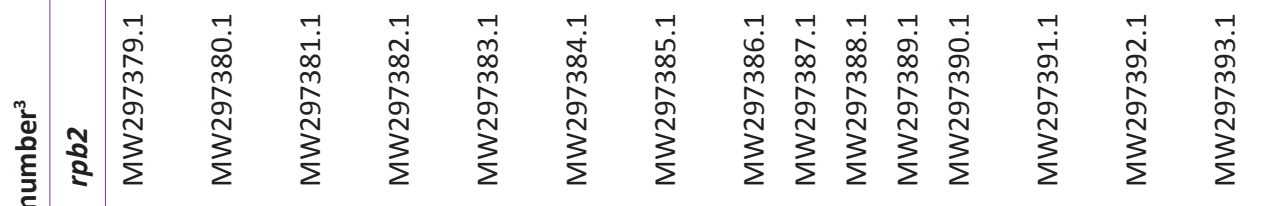

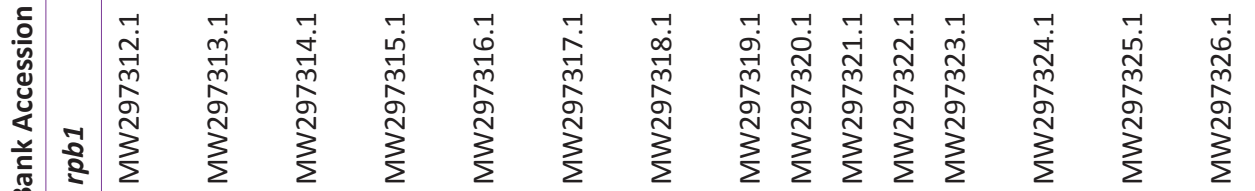

ธั

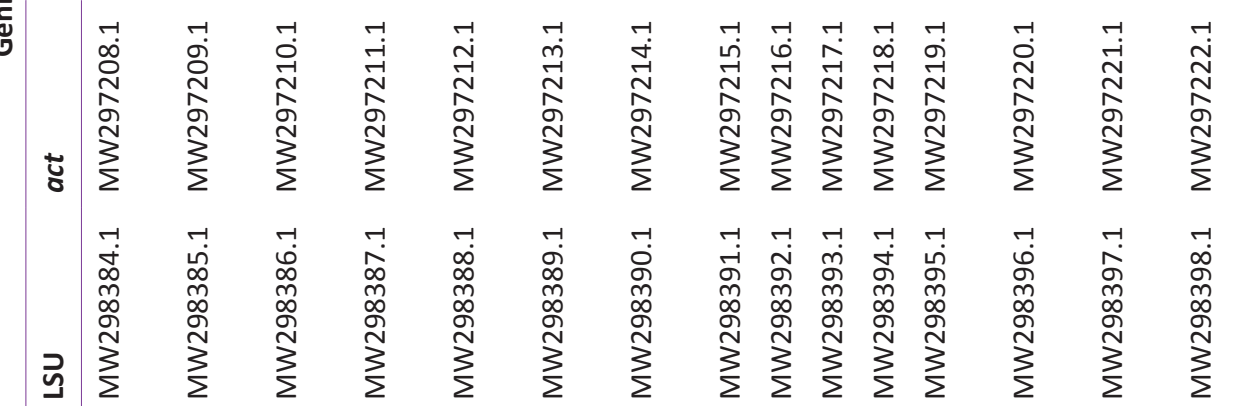

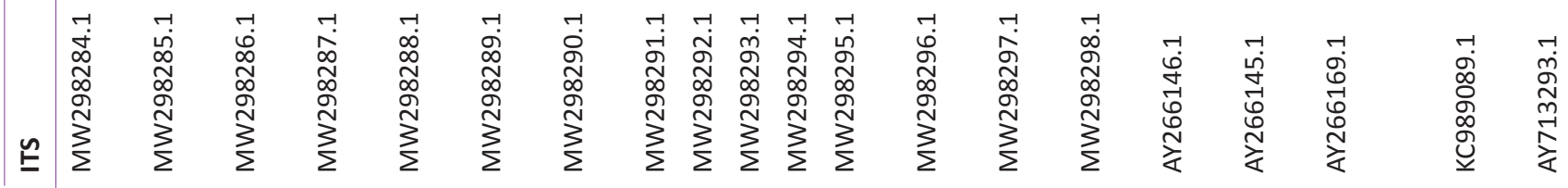

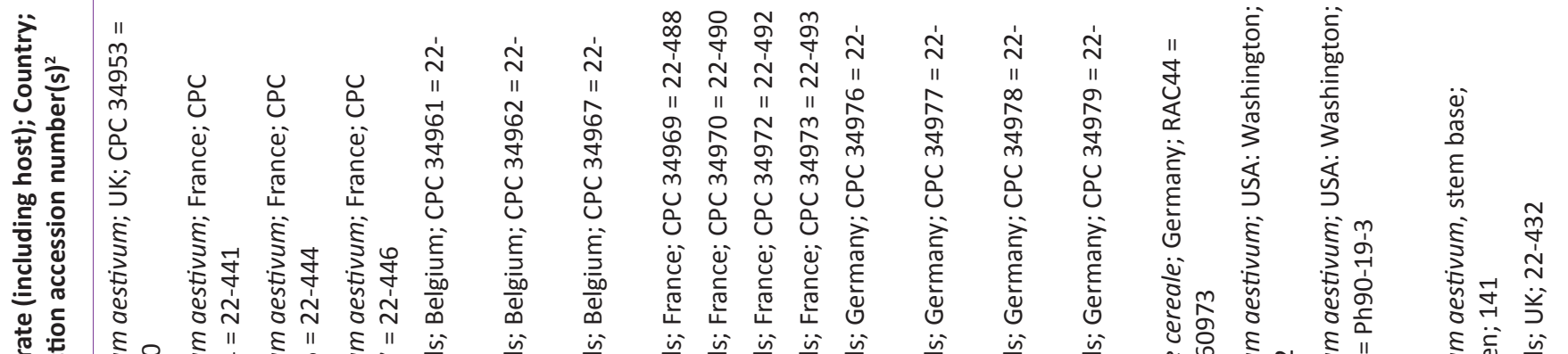

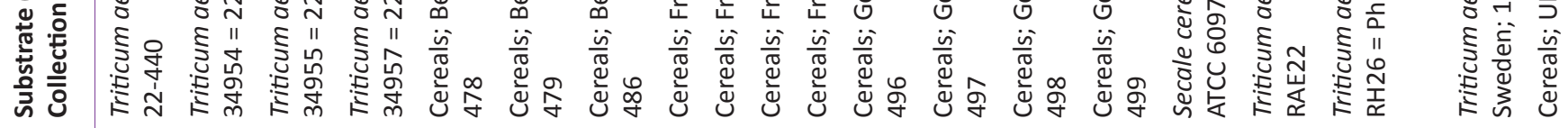

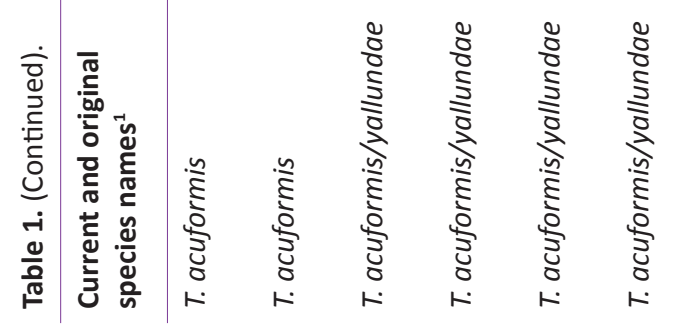

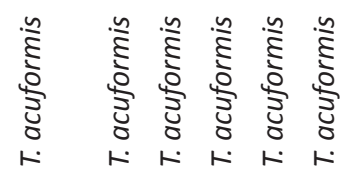

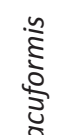




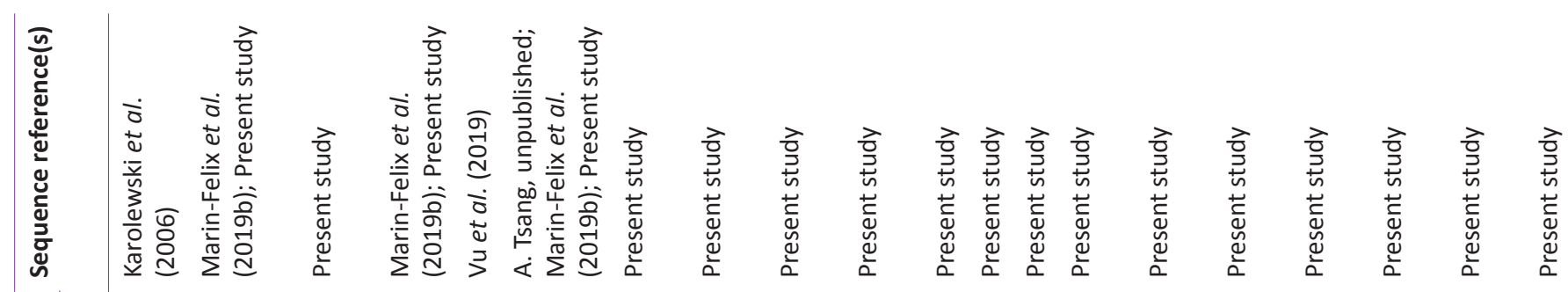

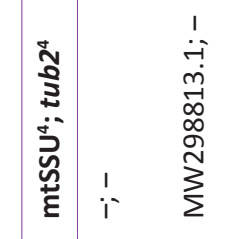

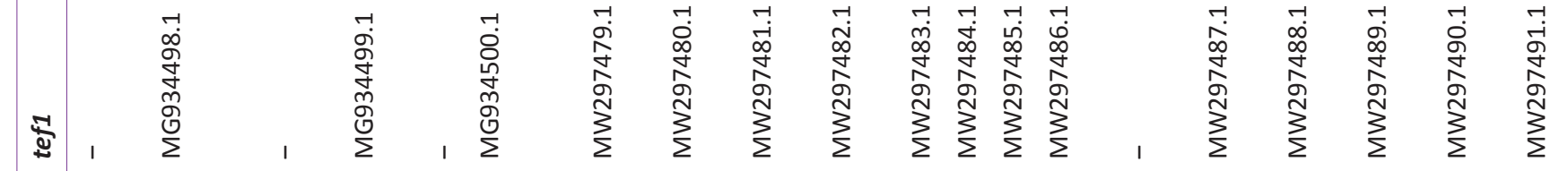

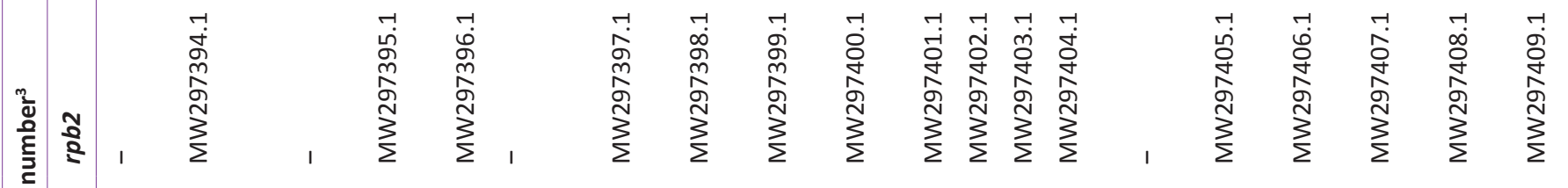

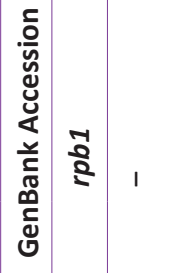

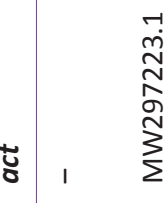

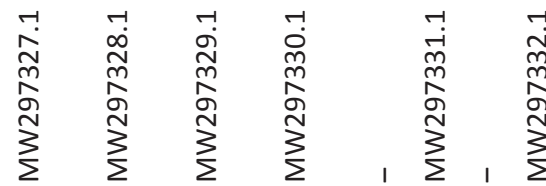

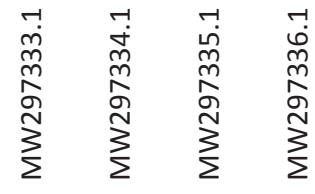

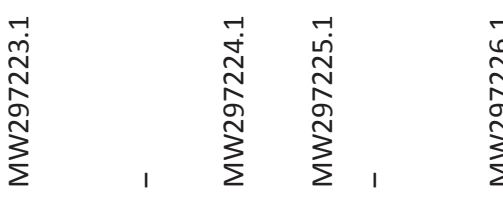

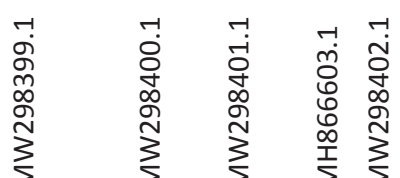

3.

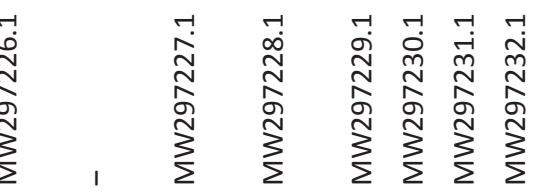

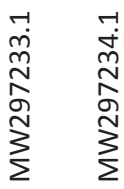

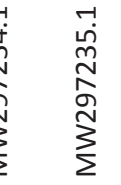

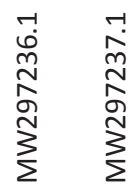

气

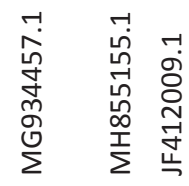

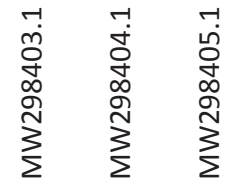

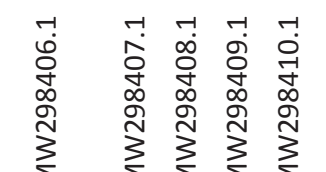

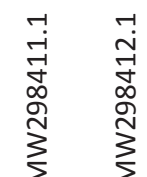

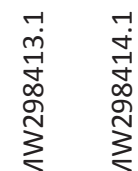

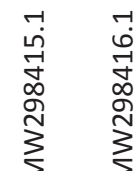

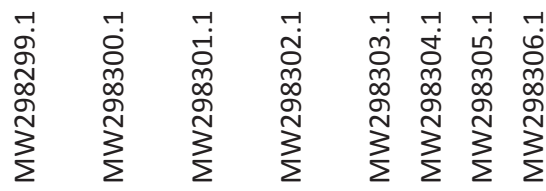

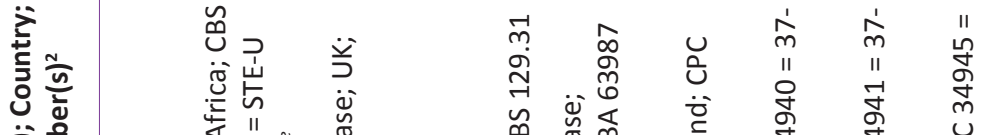

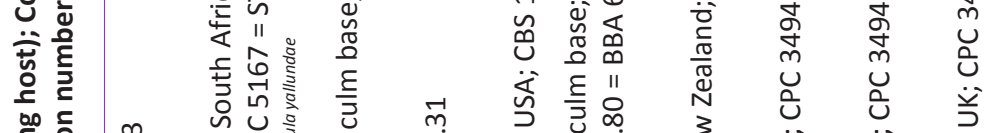

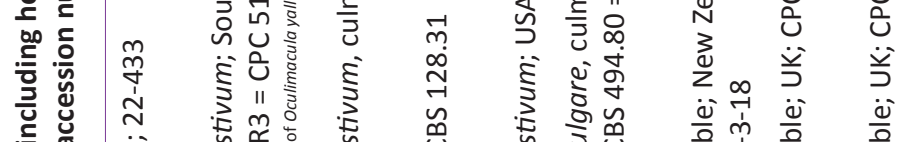

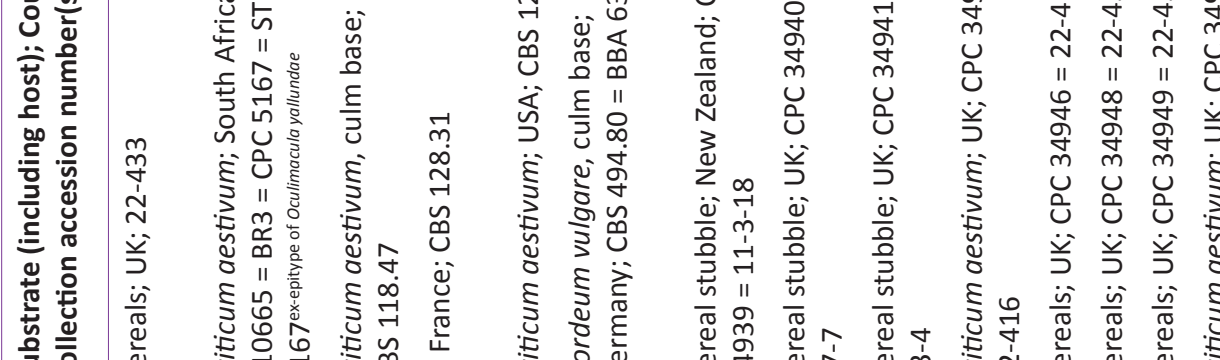

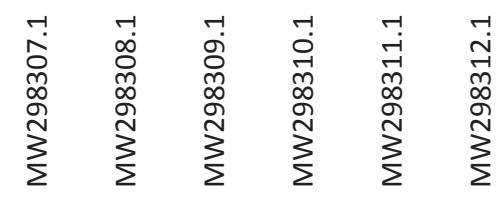

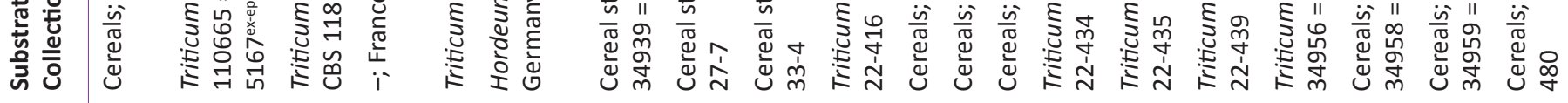

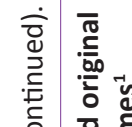

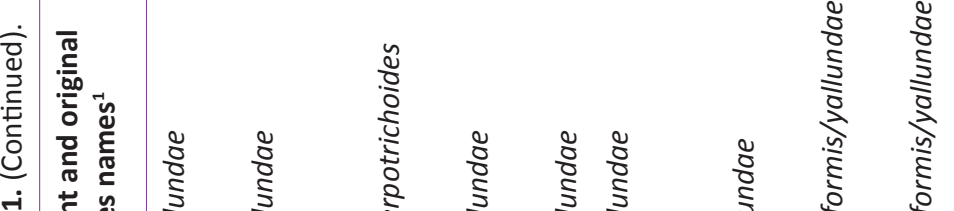

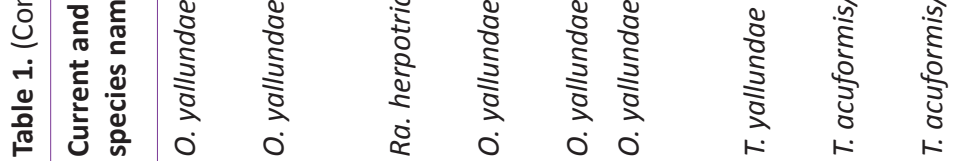

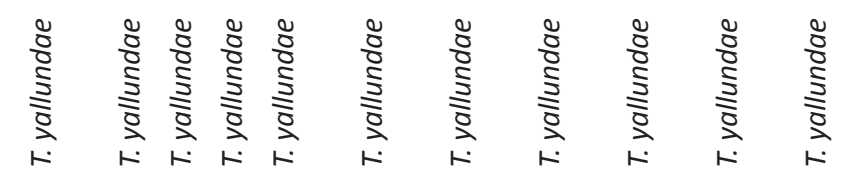



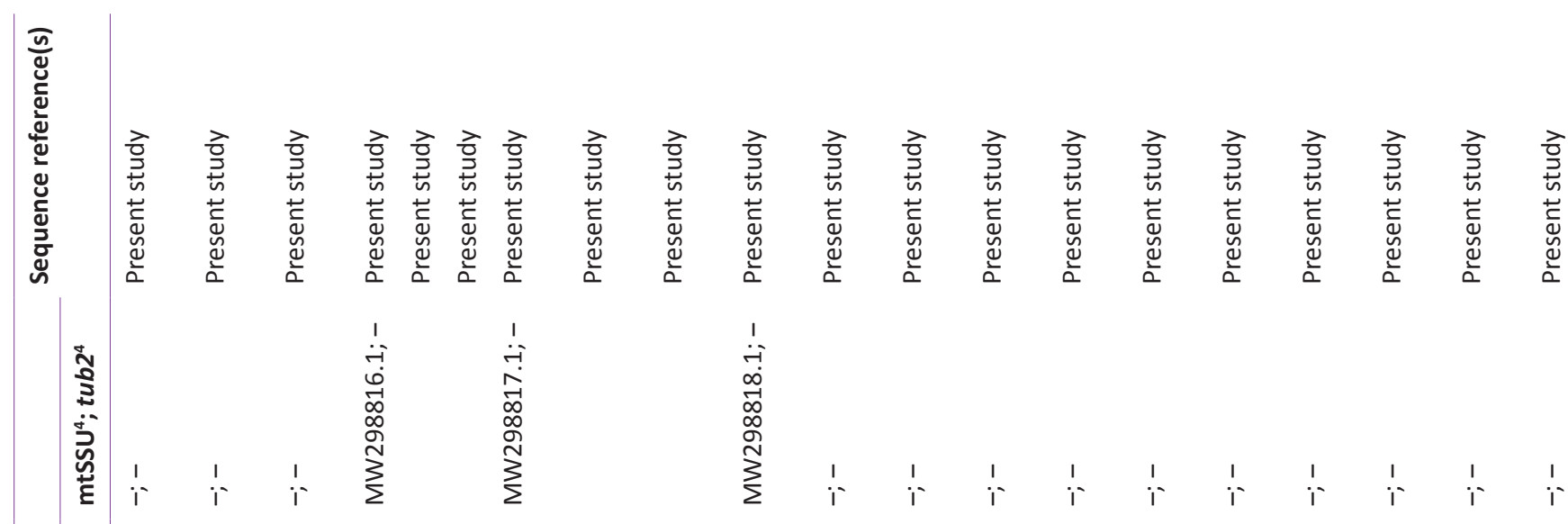

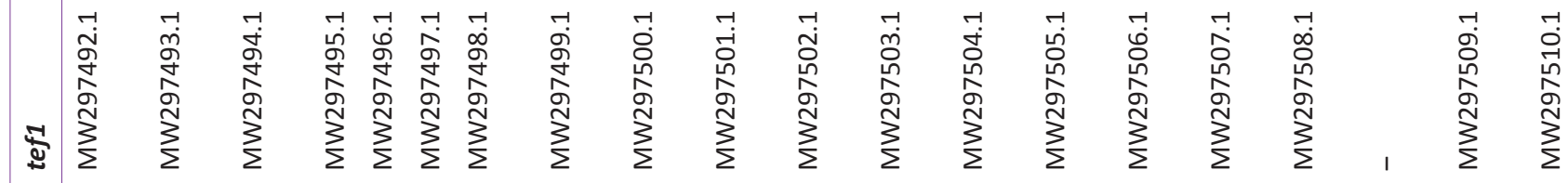

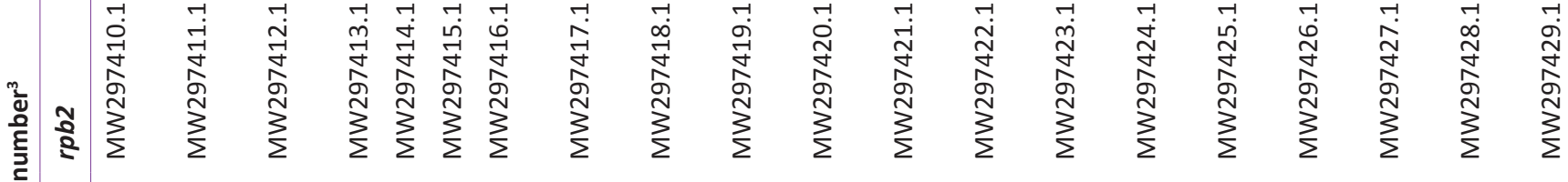

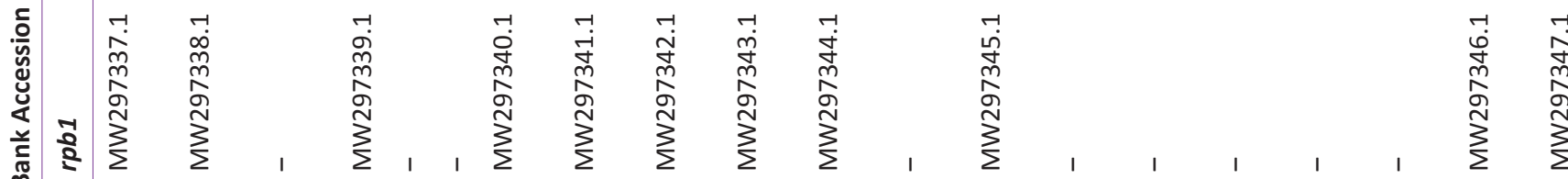

ธั้

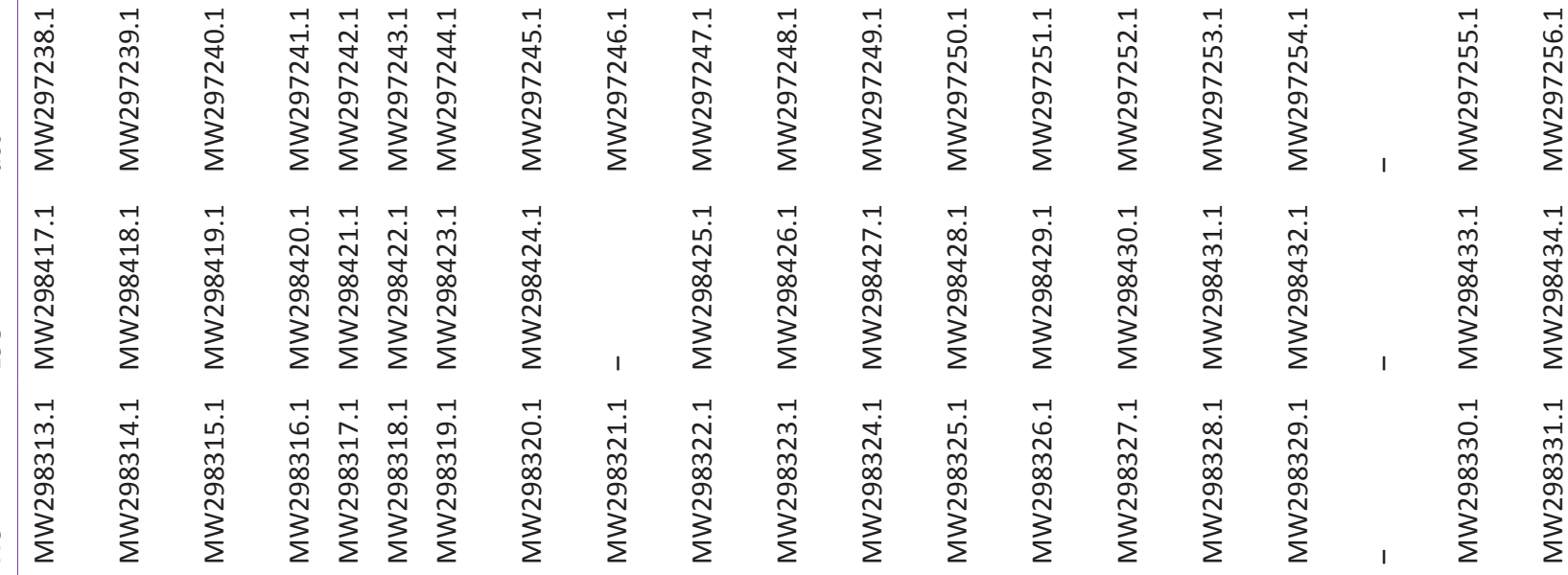

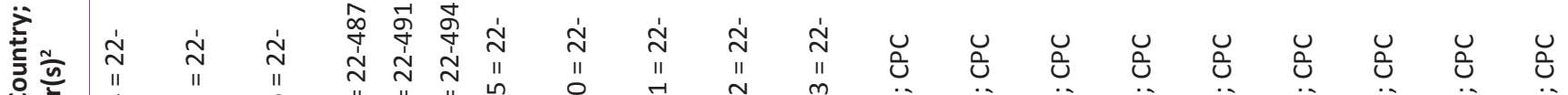

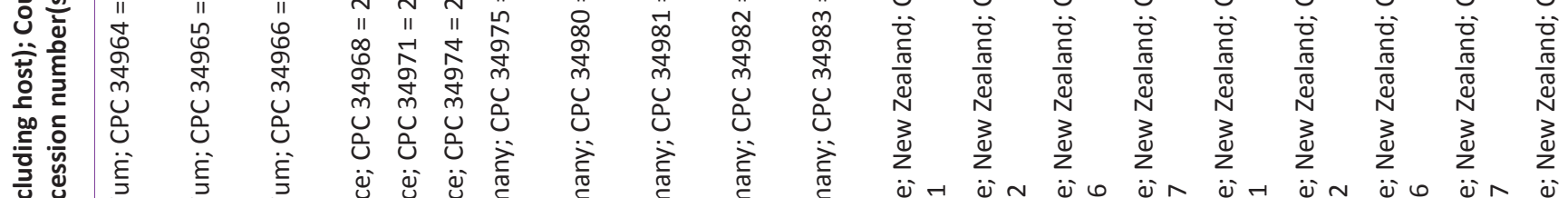

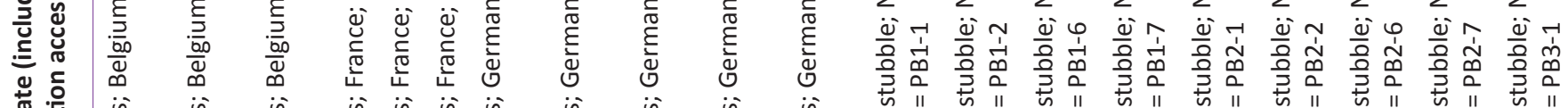

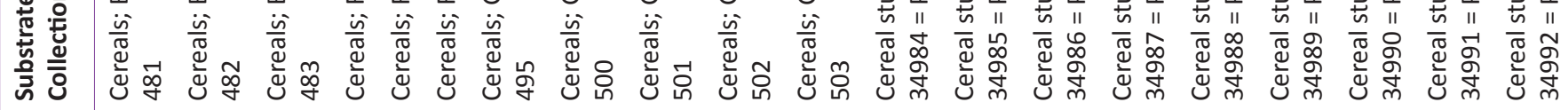

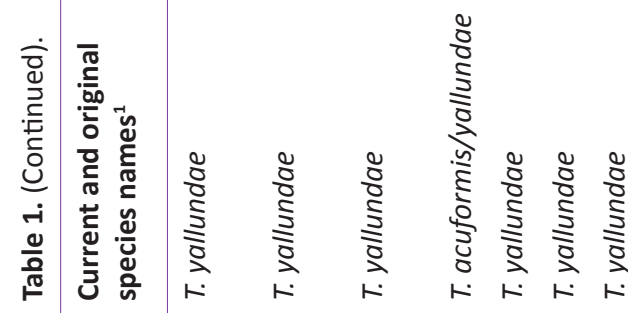

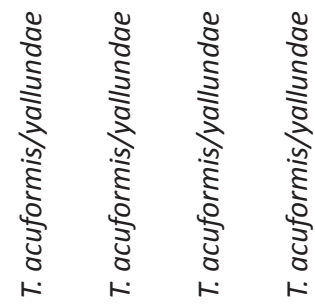




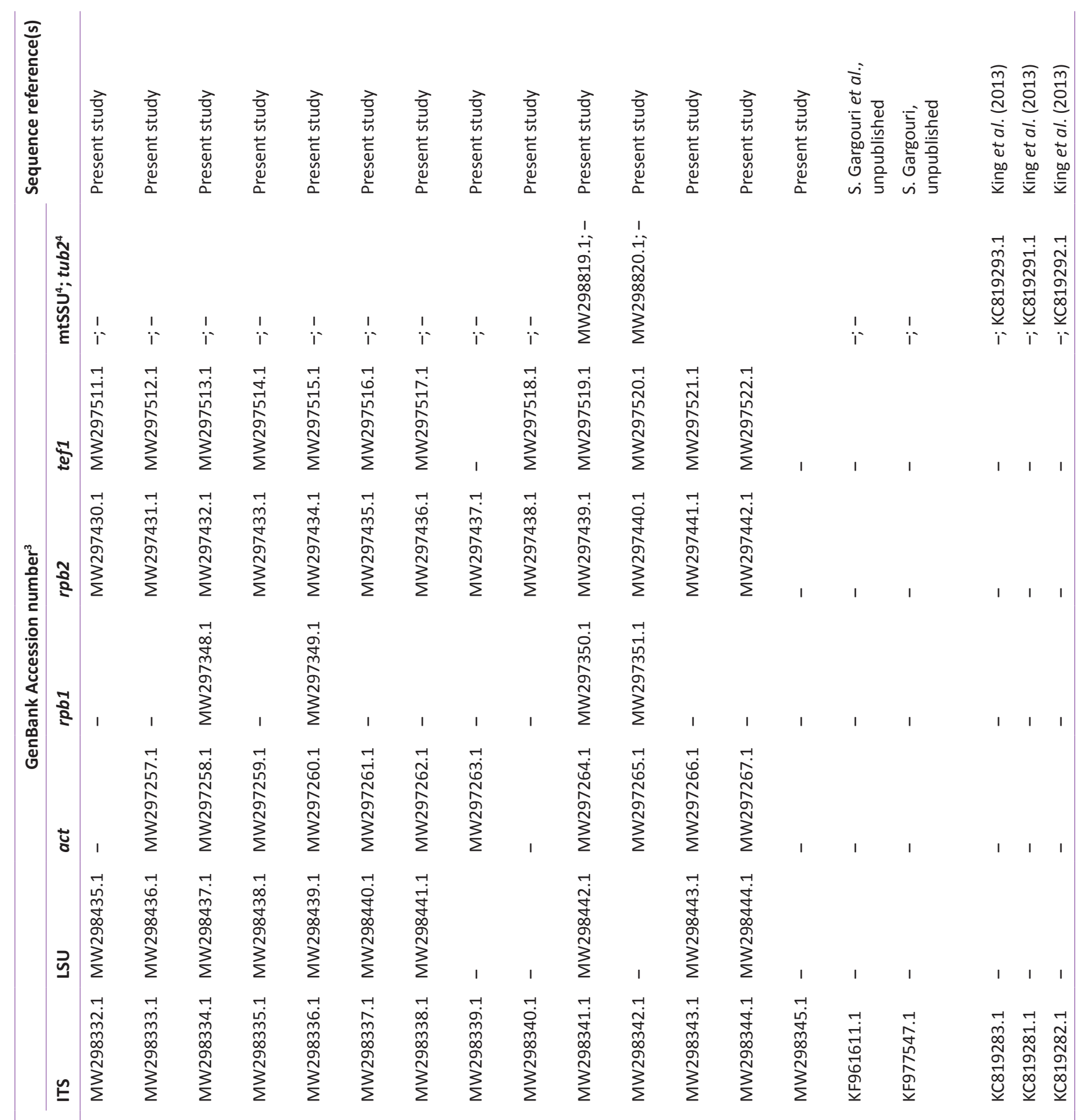

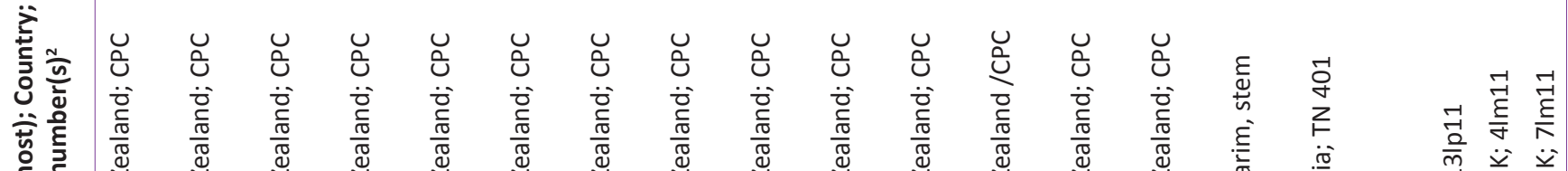

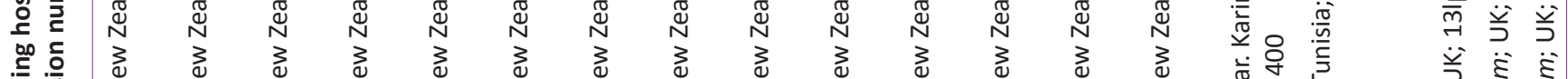

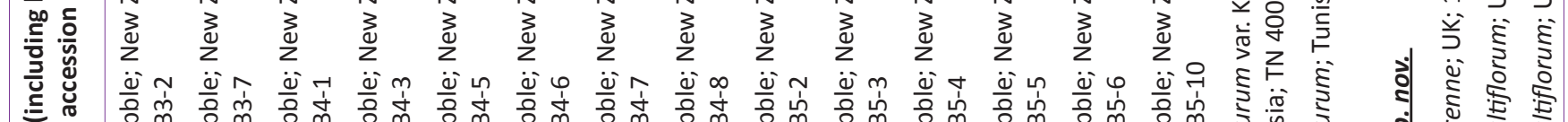

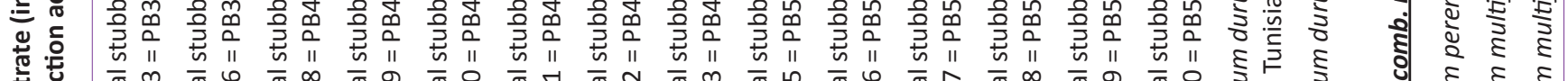

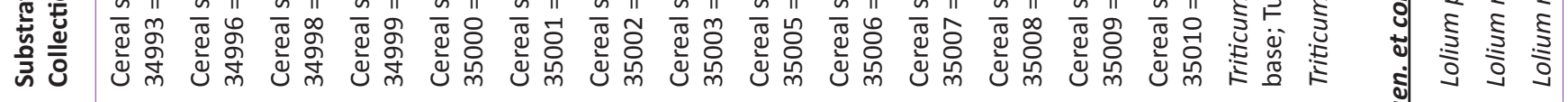

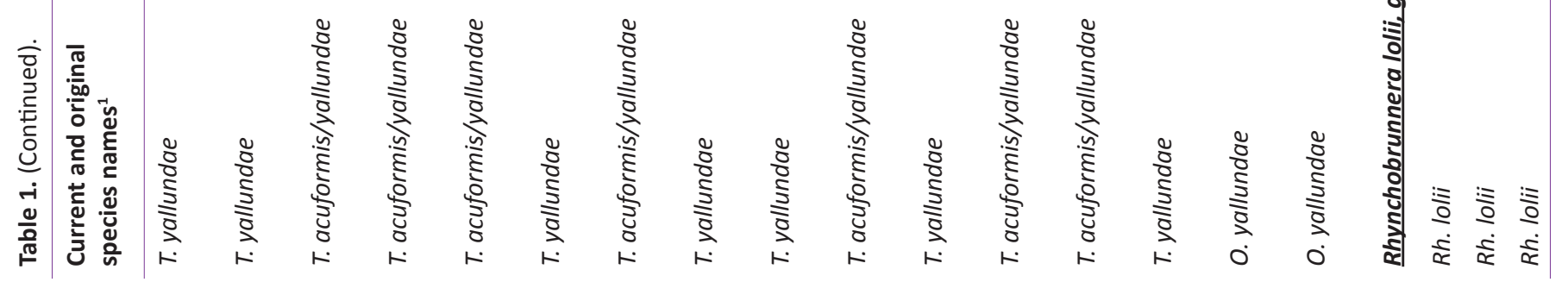




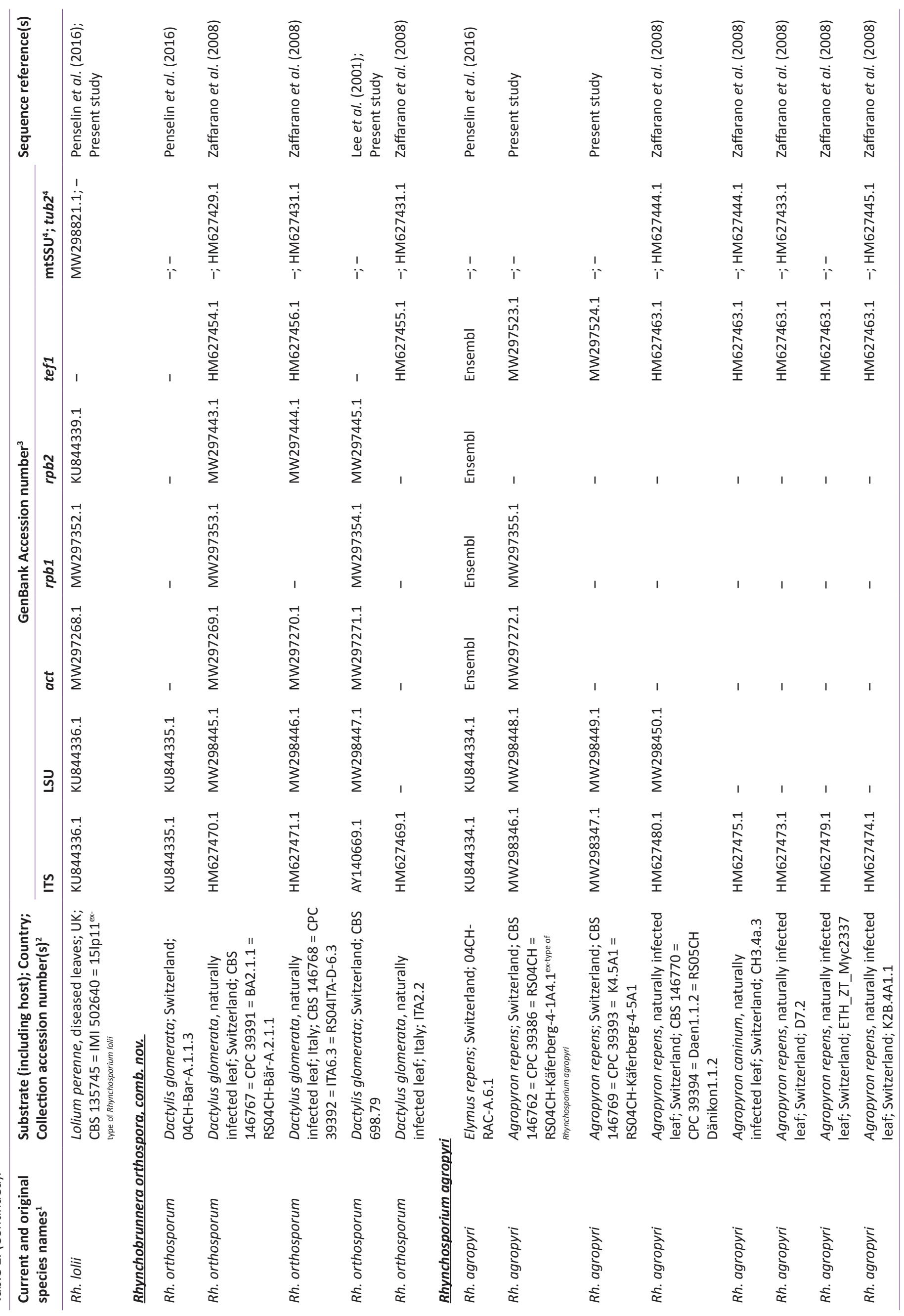




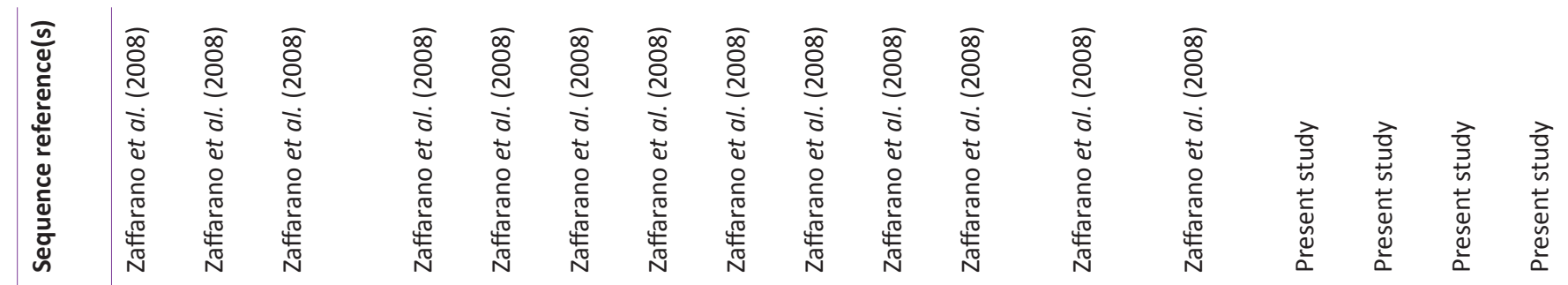

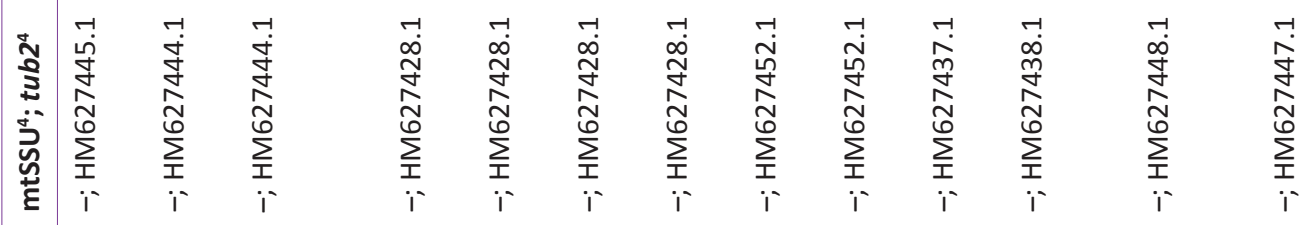

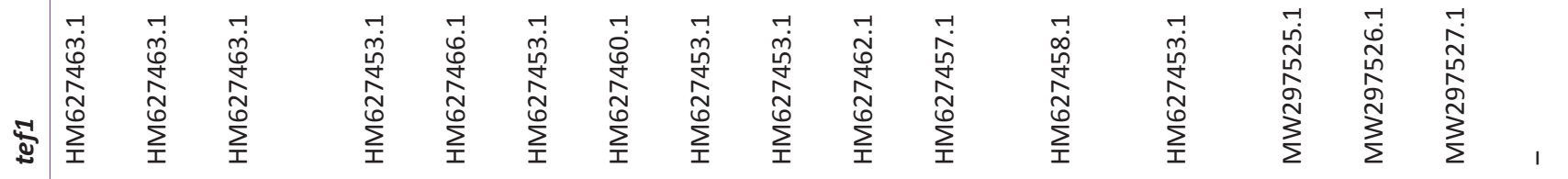

อุ

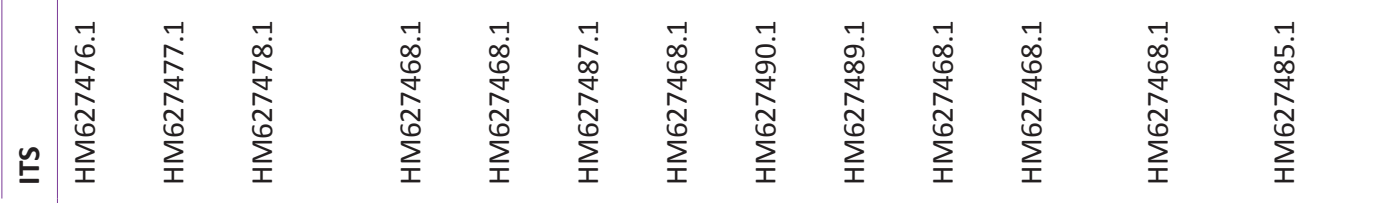

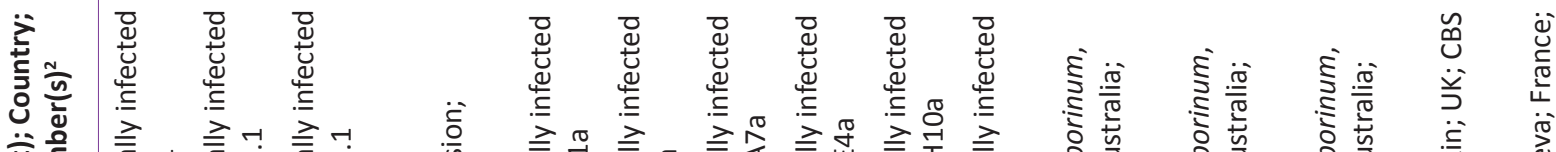

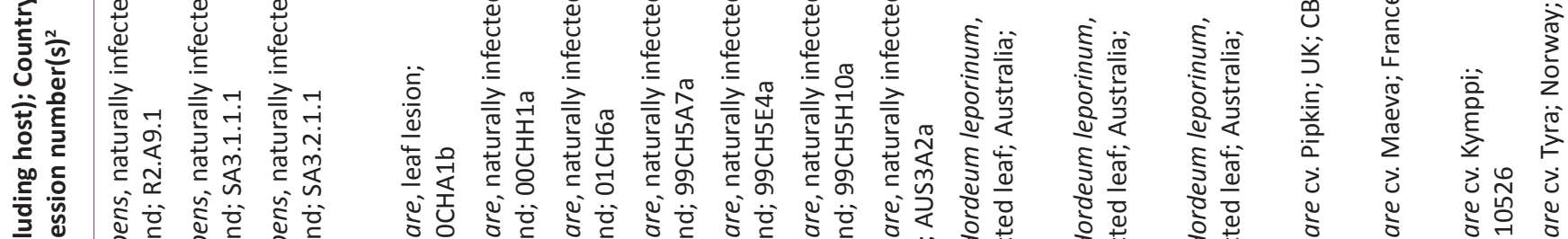

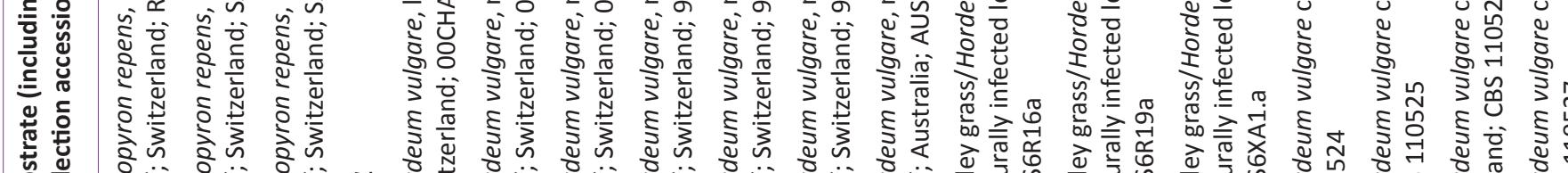

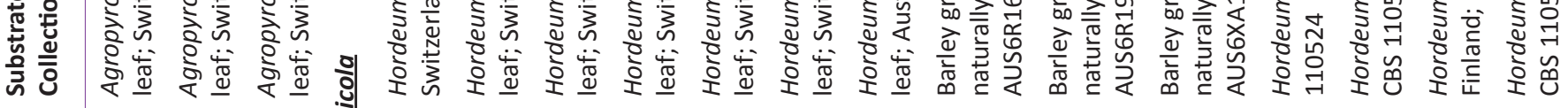

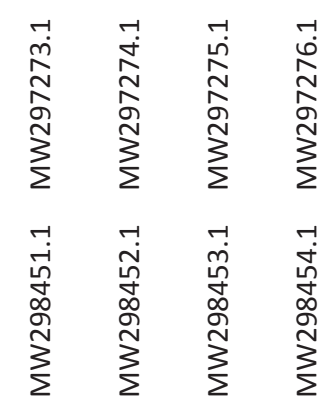




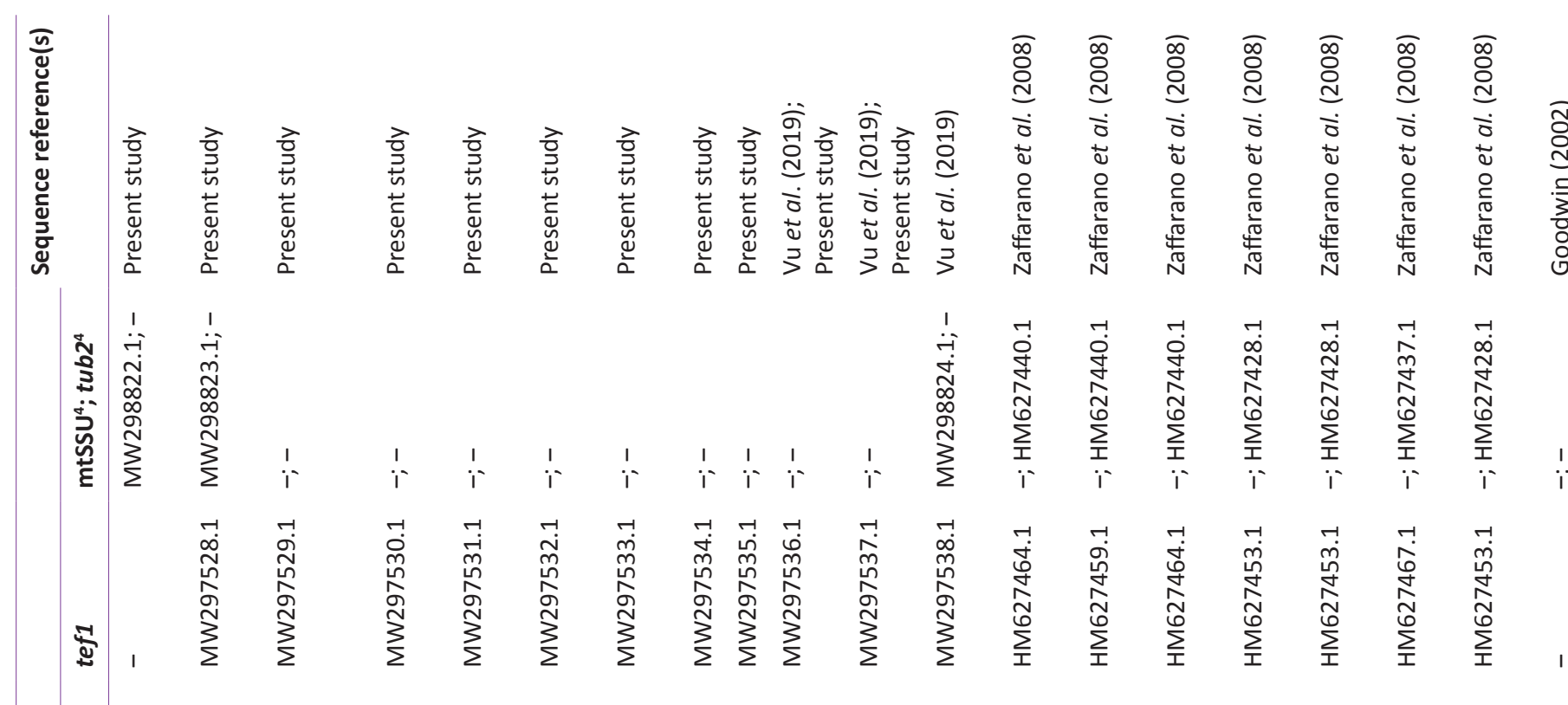

กั้

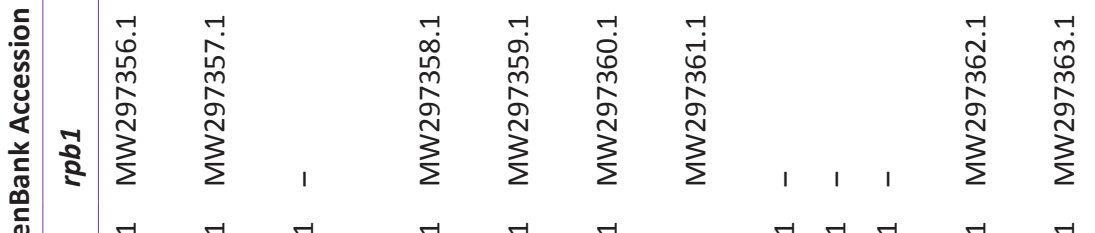

$\circlearrowleft$

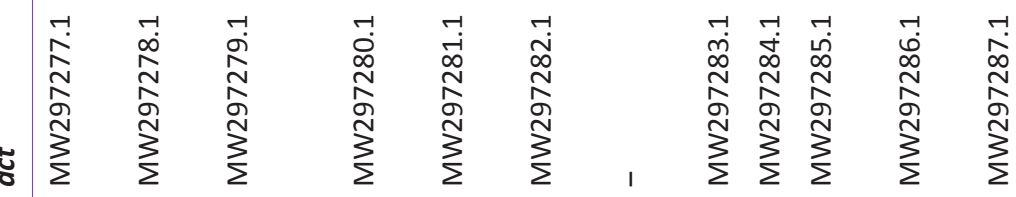

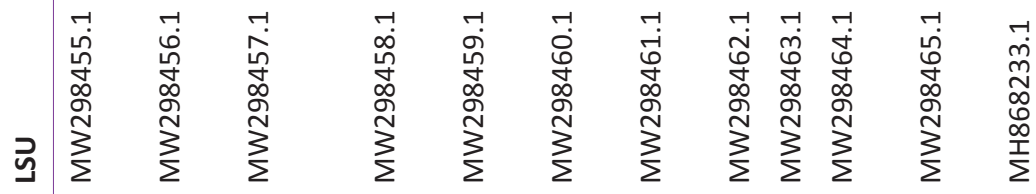

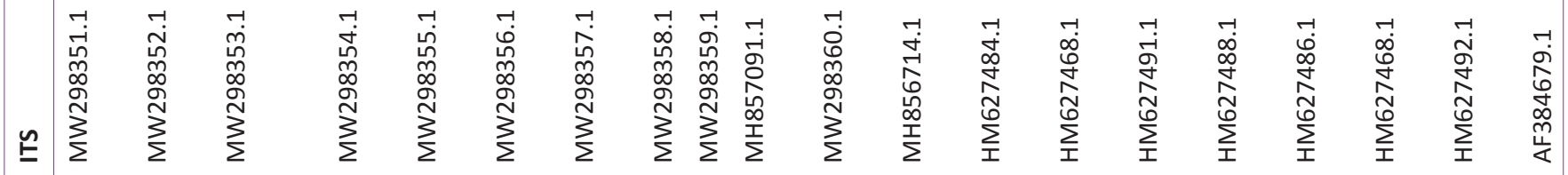

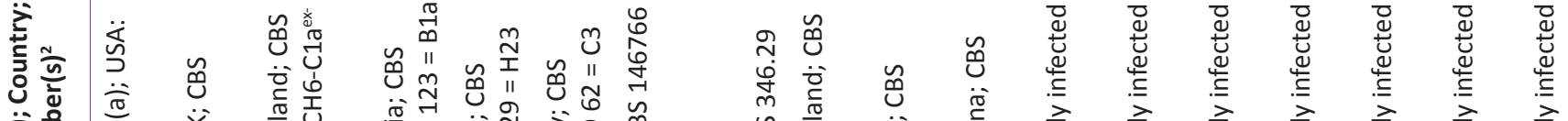

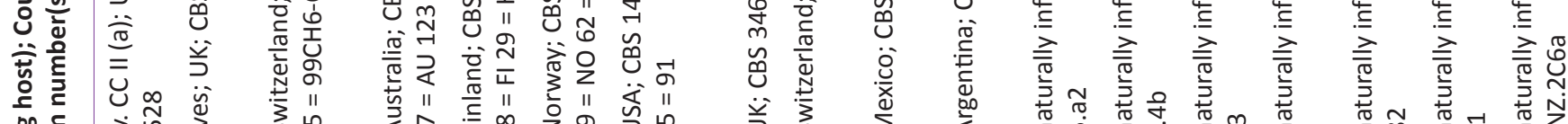

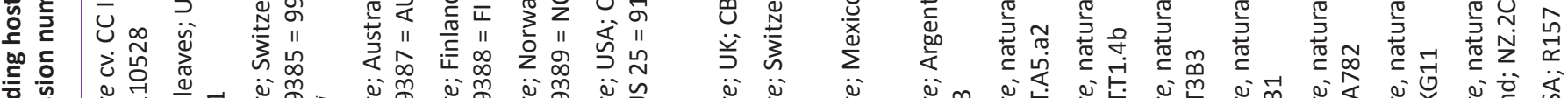

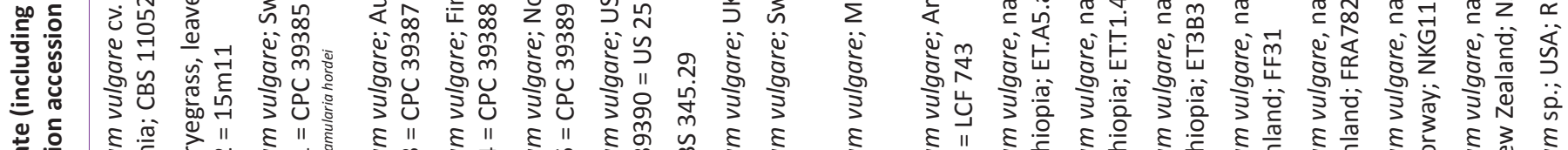

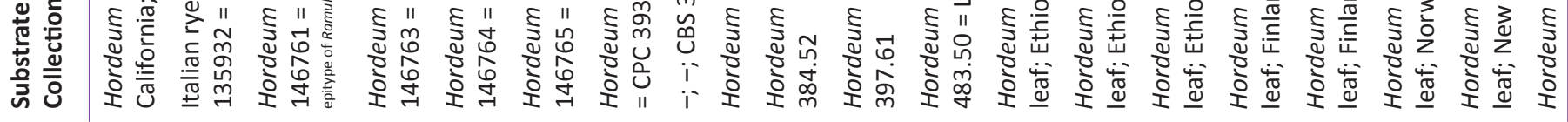

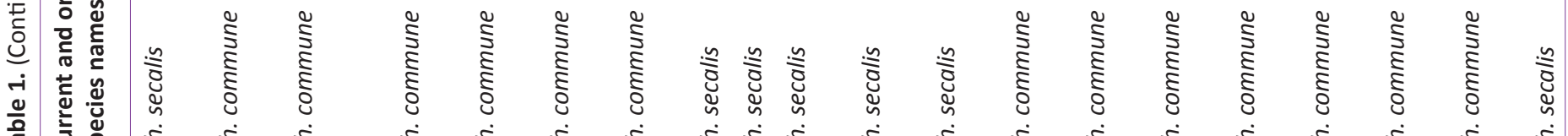
票 


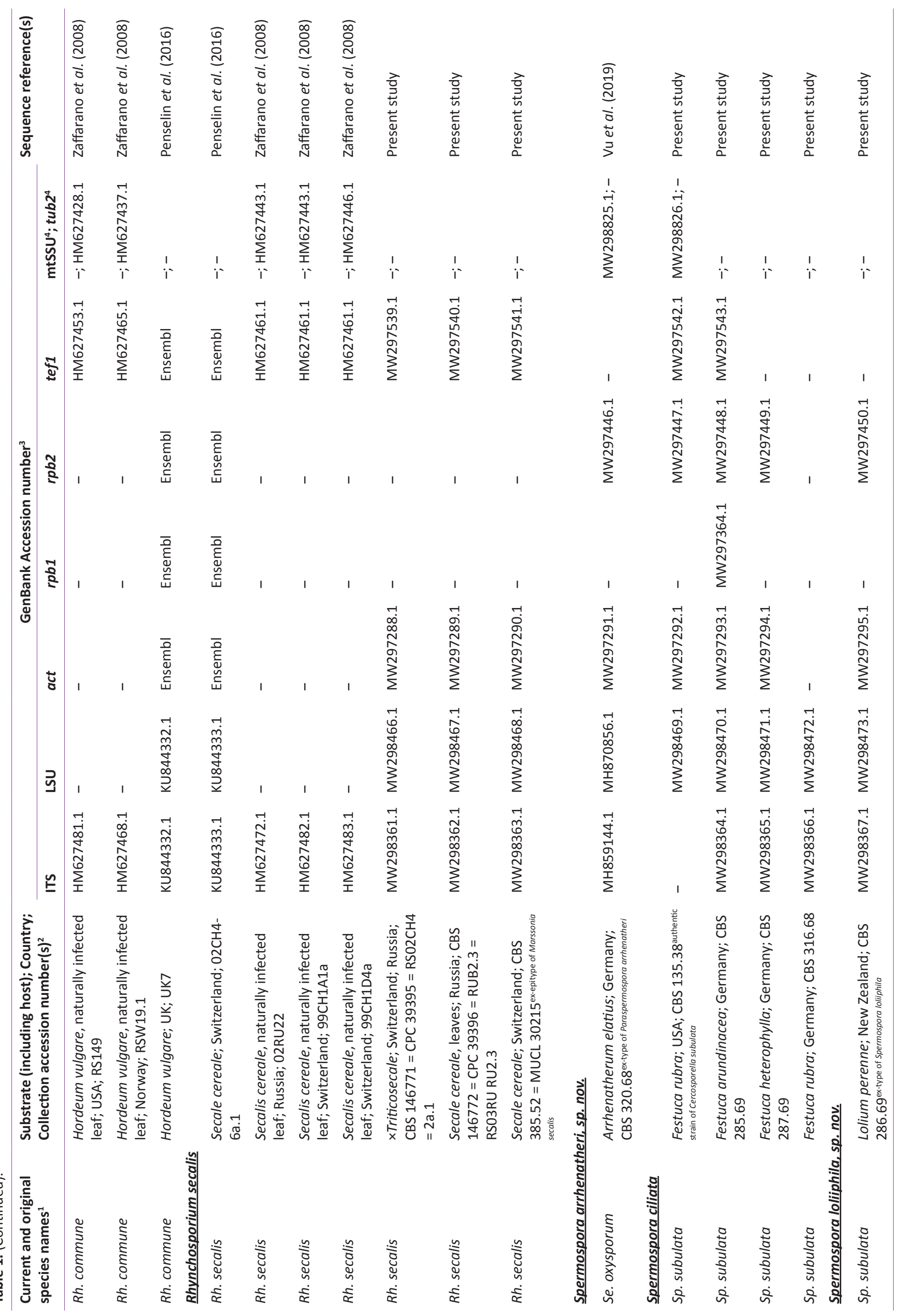




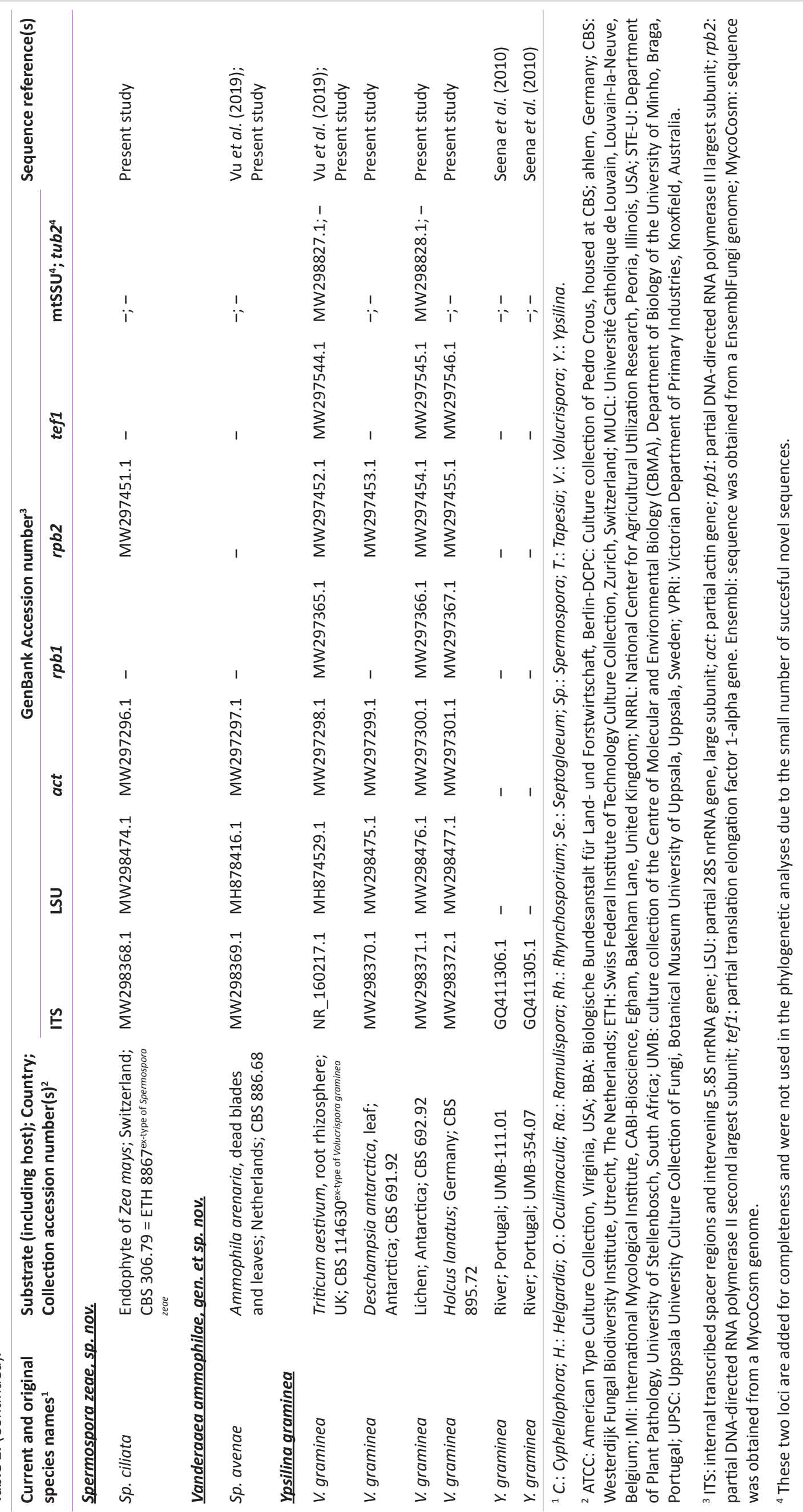


Crous et al.

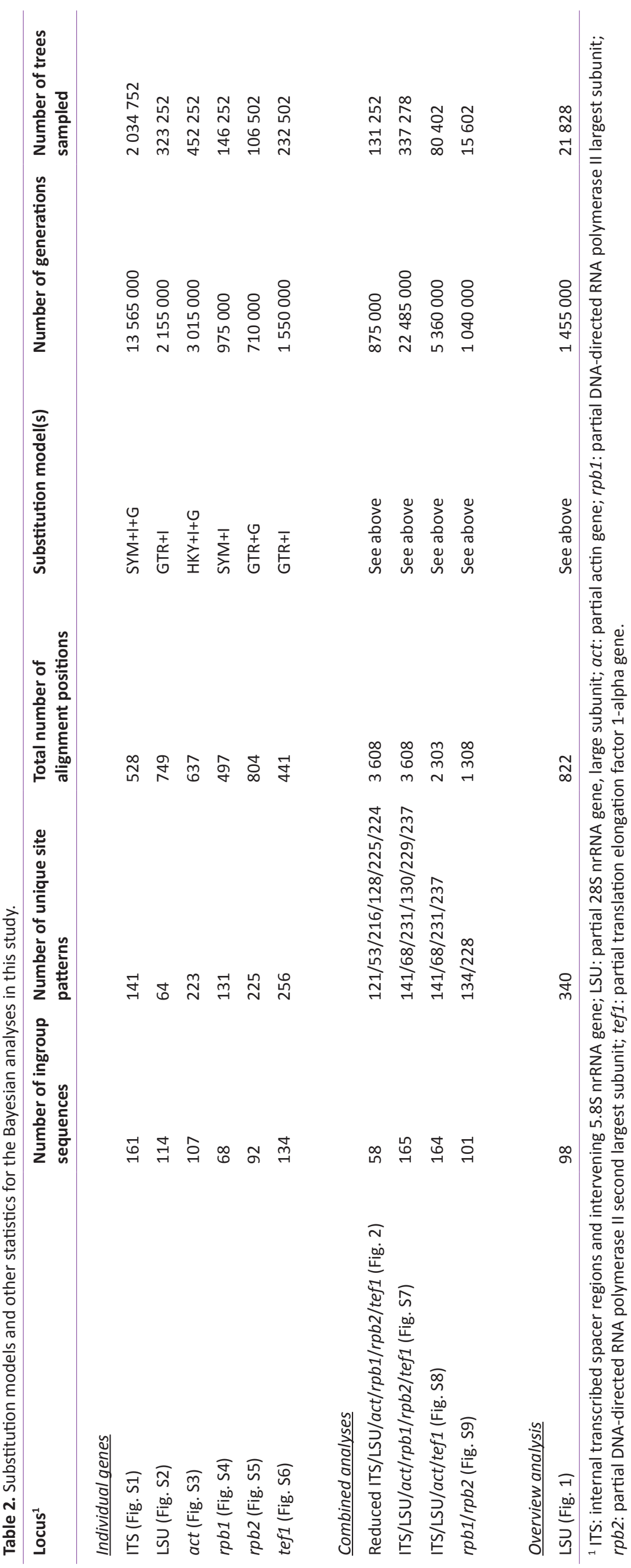




\section{Taxonomy}

Cyphellophora aestiva (Nirenberg) Crous, comb. nov. MycoBank MB838071. Fig. 3.

Basionym: Pseudocercosporella aestiva Nirenberg, Z. PflKrankh. PflSchutz 88: 246. 1981.

Synonyms: Ramulispora aestiva (Nirenberg) E.L. Stewart \& Crous, Mycol. Res. 103: 1497. 1999.

Helgardia aestiva (Nirenberg) Crous \& W. Gams, Eur. J. Pl. Path. 109: 848. 2003.

Oculimacula aestiva (Nirenberg) Crous, IMA Fungus 5: 103. 2014. Cyphellophora vermispora A. Walz \& de Hoog, Antonie van Leeuwenhoek 53: 143. 1987.

Typus: Germany, Oldenburg, on stubble of Triticum aestivum, 1979, H. Nirenberg (holotype B); culture ex-holotype BBA 64002 = CBS 497.80.

Notes: Species of Cyphellophora are characterised by having elongated, curved, one- to multiseptate conidia, and welldeveloped, flared phialides, which frequently develop directly on fungal hyphae (Crous et al. 2009). The genus includes some species which are reported from mild skin and nail infections of humans (de Hoog et al. 2000, Réblová et al. 2013), while others occur widespread in nature and have been isolated from soil, plants, water and other substrates (Feng et al. 2014, Crous et al. 2019a). The morphology of Cyphellophora aestiva (CBS 497.80 from Triticum aestivum, Germany) is identical to $C$. vermispora (CBS 227.86) described from $T$. aestivum stalks collected in Germany (ex-type culture CBS 228.86; Walz \& de Hoog 1987). The ITS sequence of CBS 497.80 is identical (548/548 bp) to ITS sequence of the ex-type of $C$. vermispora (MUCL $43739=\mathrm{CBS}$ 228.86; GenBank NR_121463) and it differed one nucleotide from the ITS sequence of $C$. vermispora culture CBS 227.86 (GenBank JQ766425); it is 617/624 (99\%, including two gaps) similar to the ITS sequence of the ex-type of $C$. laciniata (CBS 190.61; GenBank NR_121335). The LSU sequence differs with a single nucleotide over 763 bp from CBS 227.86 (GenBank JQ766474) and with two indels over $889 \mathrm{bp}$ from the ex-type of C. vermispora (CBS 228.86 = MUCL 43739; GenBank MH873637); it is $881 / 885$ (99\%) similar to the LSU sequence of the ex-type of C. laciniata (CBS 190.61; GenBank FJ358239). The tub2 sequence is identical (385/385 bp) to that of $C$. vermispora culture CBS 227.86 (GenBank JQ766331) and differs two nucleotides from the sequence of the ex-type of $C$. vermispora (368/370 bp, CBS 228.86 = MUCL 43739; GenBank JQ766332); it is 341/387 (88\%, including four gaps) similar to the tub2 sequence of the ex-type of C. laciniata (CBS 190.61; GenBank JQ766329).

Helgardiomyces Crous, gen. nov. MycoBank MB838072.

Etymology: Helgardiomyces, composed of Helgard, named after the German mycologist and phytopathologist, Dr Helgard I. Nirenberg, who first recognized the distinctiveness of these fungi on cereals, and-myces (fungus).

Mycelium consisting of hyaline, smooth, septate, branched hyphae. Conidiophores mostly solitary to aggregated, rarely branched, hyaline, smooth, with terminal conidiogenous cells that have apical sympodial proliferation, and inconspicuous scars. Conidia long, flexuous, subcylindrical, hyaline, smooth, multiseptate, apex subobtuse, base truncate, hila unthickened.

Type species: Helgardiomyces anguioides (Nirenberg) Crous

\section{Ex-type culture: CBS 496.80.}

Helgardiomyces anguioides (Nirenberg) Crous, comb. nov. MycoBank MB838073.

Basionym: Pseudocercosporella anguioides Nirenberg, Z. PflKrankh. PflSchutz 88: 246. 1981.

Synonyms: Ramulispora herpotrichoides var. anguioides (Nirenberg) U. Braun, Nova Hedwigia 56(3-4): 433. 1993.

Ramulispora anguioides (Nirenberg) Crous, S. Afr. J. Bot. 61: 47. 1995.

Helgardia anguioides (Nirenberg) Crous \& W. Gams, Eur. J. PI. Path. 109: 846. 2003.

Oculimacula anguioides (Nirenberg) Crous, IMA Fungus 5: 103. 2014.

Typus: Germany, Göttingen, culm base of Triticum aestivum, 1979, H. Nirenberg (holotype B); culture ex-holotype BBA 64003 $=$ CBS 496.80 .

Notes: Colonies differ from those of Oculimacula in that they are fast growing, and dull pinkish on PDA, velvety, with entire margin. Conidia are long and flexuous, up to $280 \mu \mathrm{m}$ in length, and pluriseptate (Nirenberg 1981). In contrast to Oculimacula, $H$. anguioides is weakly aggressive to wheat (Bateman 1988). The species formed a fully or well-supported lineage in most analyses of the loci for which sequences were available (ITS, act, rpb2, tef1; Figs 2, S1, S3, S5, S6; multigene phylogenies Figs 2,
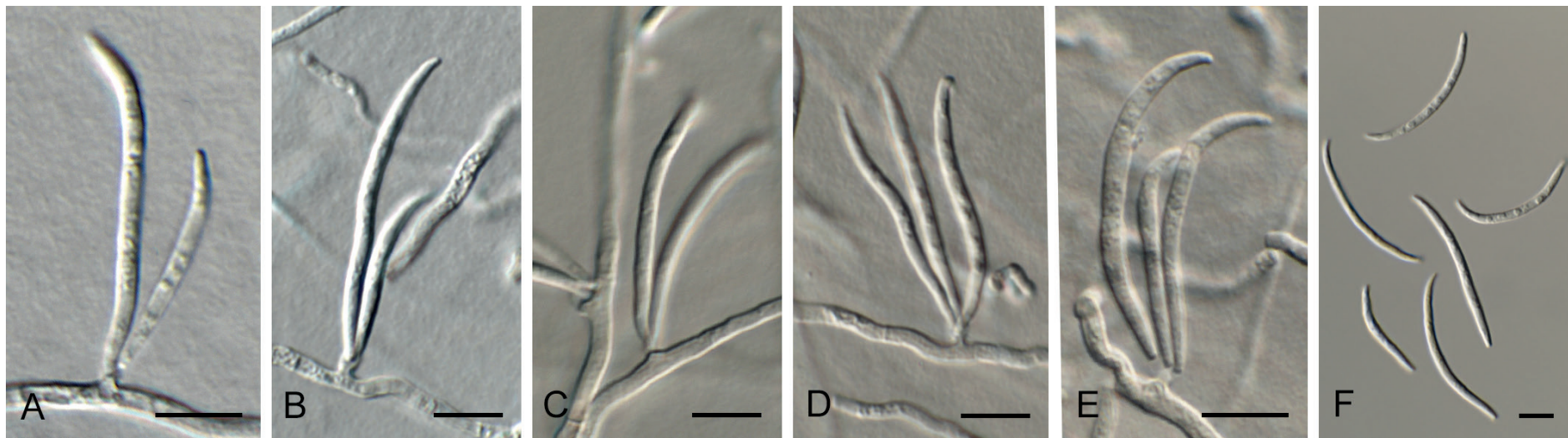

Fig. 3. Cyphellophora aestiva (CBS 497.80). A-E. Hyphae with phialides giving rise to clusters of conidia. F. Conidia. Scale bars $=10 \mu \mathrm{m}$. 
S7-S9), with the exception of LSU where it was not well resolved (Figs 1, S2).

Neospermospora Crous \& U. Braun, gen. nov. MycoBank MB838074.

Etymology: Referring to its morphological similarity to Spermospora.

Phytopathogenic, causing leaf spots. Mycelium internal, hyaline to olivaceous, septate, branched, becoming swollen in epidermal cells, and at times aggregating into swollen, vesicular conidiogenous cells, hyaline to pale olivaceous, smooth. Conidiogenous cells form narrow, blunt or pointed penetration tubes that penetrate the outer epidermal cells, giving rise to a single, terminal conidium. Conidia narrowly fusoid with long narrow rostrum, septate, not constricted at septa, straight to curved, often with single filiform sub-basal appendage, hyaline, smooth, with obconically truncate base.

Type species: Neospermospora avenae (R. Sprague \& Aar.G. Johnson) Crous \& U. Braun

Reference culture: CBS 227.38.

Neospermospora avenae (R. Sprague \& Aar.G. Johnson) Crous \& U. Braun, comb. nov. MycoBank MB838075. Fig. 4.

Basionym: Pseudodiscosia avenae R. Sprague \& Aar.G. Johnson, Mycologia 28(2): 183. 1936.

Synonym: Spermospora avenae (R. Sprague \& Aar.G. Johnson) R. Sprague, Diseases of Cereals and Grasses of North America: 430. 1950.
Typus: USA, Washington, Klichitat Co., High Prairie, on Avena sativa, 10 Feb. 1934, R. Sprague [lectotype, designated by Braun (1995: 238), K]; isolectotypes BPI 407544, 407549, CINC-F0008022, ISC-F-0098103, K, MICH 5608, NY01087070, OSC 8036, RMS 0024665, WIS-F-0033535. USA, Oregon, near Corvallis, on A. sativa, Mar. 1938, R. Sprague (epitype designated here CBS 227.38, MBT394907, preserved as a metabolically inactive culture; culture ex-epitype CBS 227.38reference strain deposited by R. Sprague).

Additional isolates examined: Australia, Victoria, Maryborough, on leaves of Avena sativa, 8 Sep. 2014, P. Zwer, VPRI 42798; Victoria, Wal Wal, on leaves of $A$. sativa, J. Edwards, 3 Oct. 2016, VPRI 42892a. Japan, H. Kurata, No. 4320, MUCL $8143=$ CBS 388.64.

Description and illustration of characteristics in vivo: Braun (1995: 238 and 239, fig. 220).

Notes: Neospermospora avenae causes red leather leaf disease of oats, reducing grain yield and hay quality, and has been reported from Europe, the USA, Turkey and Australia (Cunningham 1990, Zaveri et al. 2020). Based on the isolates included in the phylogeny, it appears that an undescribed species of Neospermospora (CBS 388.64) also occurs on Avena in Japan. This isolate is genetically slightly different from the other included cultures of $N$. avenae with the following number of substitutions compared to the other sequenced strains: three (and one indel) in ITS, seven in LSU, 10 in act, two in rpb1, 11 in rpb2, and 17 substitutions in tef1.

Cultures of $N$. avenae formed a microconidial synanamorph in culture with hyaline, aseptate conidia. The species formed a fully supported lineage in all analyses of different combinations of the
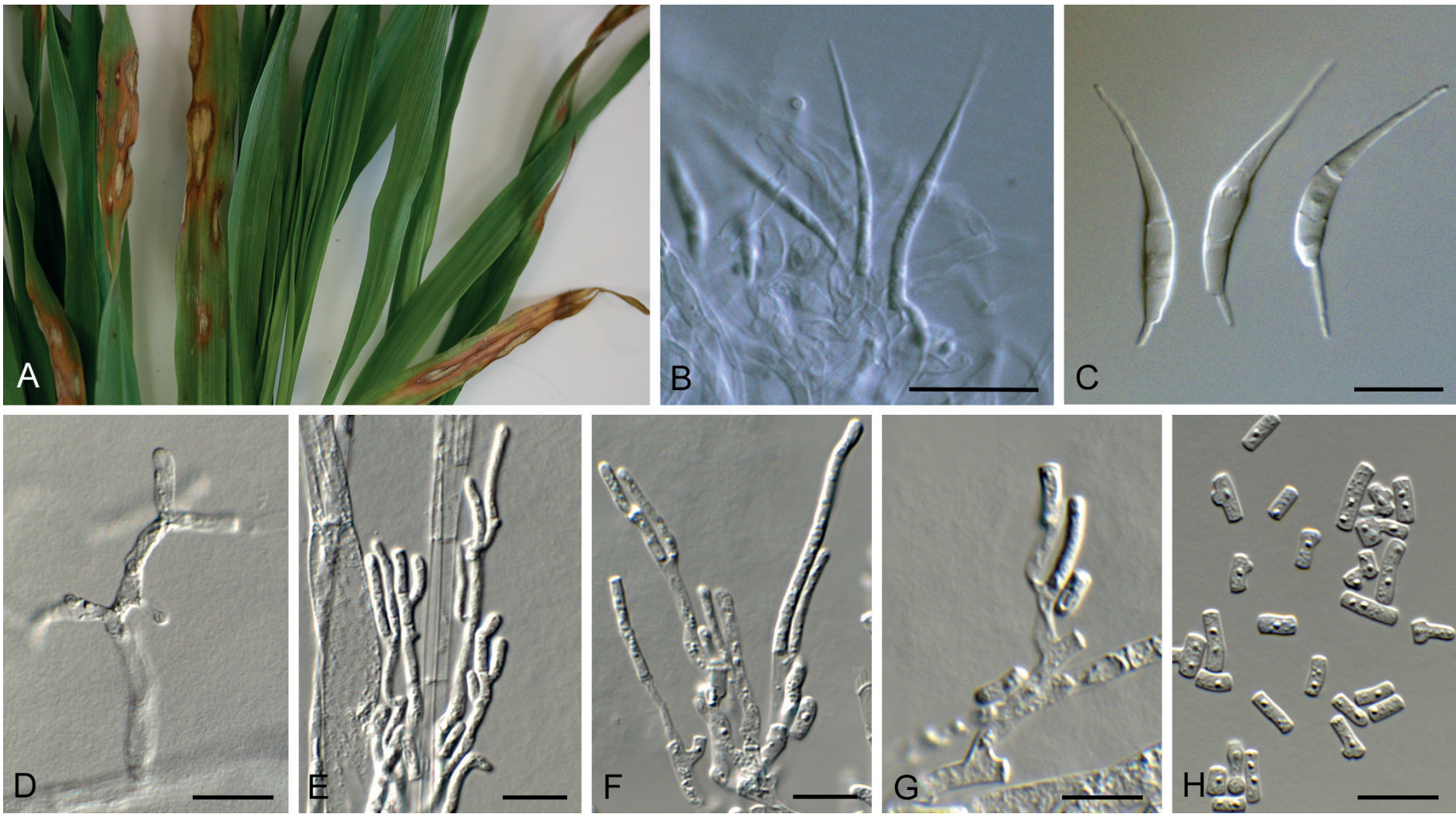

Fig. 4. Neospermospora avenae. A-C (VPRI 42798). Disease symptoms on Avena sativa. B. Conidiogenous cells giving rise to macroconidia. C. Macroconidia. D-H (CBS 227.38). Hyphae giving rise to a microconidial synasexual morph. Scale bars $=10 \mu \mathrm{m}$. 
six loci studied here (Figs 1, 2, S1-S9). Sprague \& Johnson (1936) failed to designate a holotype for Pseudodiscosia avenae. They only cited several "co-types" which required lectotypification (Braun 1995). That is followed here for designating an epitype obtained from a living culture that served as the source of the sequence data.

Oculimacula Crous \& W. Gams, Eur. J. PI. Path. 109: 845. 2003. Synonym: Helgardia Crous \& W. Gams, Eur. J. Pl. Path. 109: 845. 2003.

Ascomata 0.5-2.5 mm diam, apothecial, sessile, gregarious, circular to lobate, on a subiculum of white to dark brown hyphae, attached to substrate via a superficial mat of pale brown, thin hyphae. Disk smooth, grey with a pale grey margin, becoming emarginate and flattened to convex at maturity. Receptacle pale brown to grey-brown, cup-shaped. Medullary excipulum of multiseptate, hyaline hyphae. Ectal excipulum of thin-walled, dark brown, angular cells, becoming more elongated towards margin. Paraphyses filiform with obtuse ends, similar in length to asci. Asci 8-spored, unitunicate, clavate to subcylindrical or fusoid, with a short stalk, and an apical pore staining blue in Melzer's reagent. Ascospores bi- to multiseriate, hyaline, smooth, aseptate, fusoid to subcylindrical or clavate with rounded ends, mostly straight. Conidiophores fasciculate or solitary on superficial mycelium, or arising from pale brown stromata, subcylindrical to geniculatesinuous, rarely branching, hyaline to pale olivaceous, smooth, consisting of conidiogenous cells only, or slightly differentiated with up to 2 septa. Conidiogenous cells integrated, proliferating sympodially at apex, with inconspicuous, dense geniculations; conidiogenous loci unthickened, inconspicuous, not darkened. Conidia solitary, hyaline, smooth, arranged in slimy packets, acicular, filiform, straight to curved, one- to multiseptate, forming smaller, secondary conidia via microcyclic conidiation (Marin-Felix et al. 2019a).

Type species: Oculimacula yallundae (Wallwork \& Spooner) Crous \& W. Gams

\section{Ex-type culture: CBS 110665.}

Oculimacula acuformis (Nirenberg) Y. Marín \& Crous, Stud. Mycol. 92: 99. 2018.

Basionym: Pseudocercosporella herpotrichoides var. acuformis Nirenberg, Z. PflKrankh. PflSchutz 88: 244. 1981.

Typus: Germany, Göttingen, from culm base of Secale cereale, 1978, H. Nirenberg (holotype B); culture ex-holotype CBS 495.80.

Notes: Nirenberg (1981: 244) cited "Göttingen" as location of the holotype and CBS 495.80 as the ex-holotype culture, but under reference strains "Tübingen" was erroneously cited as locality.

Oculimacula yallundae (Wallwork \& Spooner) Crous \& W. Gams, Eur. J. Pl. Path. 109: 846. 2003. Fig. 5.

Basionym: Tapesia yallundae Wallwork \& Spooner, Trans. Brit. Mycol. Soc. 91: 703. 1988.

Typus: Australia, South Australia, Yallunda Flat, on Triticum, 18 Nov. 1986 (holotype K(M)233697); isotype DAR 58247 (ex ADW 16996). South Africa, Western Cape Province, Moorreesburg, on stubble of Triticum aestivum, 1991, F. Bester (epitype designated here CBS 110665, МBT394908, preserved as metabolically inactive culture; culture ex-epitype CBS 110665).

Notes: Oculimacula was introduced to accommodate sexual morphs of the eyespot diseases of wheat and barley, previously classified in Tapesia, while the asexual morphs were accommodated in Helgardia (Crous et al. 2003). Following the one fungus one name system, Johnston et al. (2014) proposed the name Oculimacula for the eyespot disease complex. Oculimacula is herewith reduced to two species, $O$. acuformis and $O$. yallundae. The genus formed a fully or highly supported lineage for most of the loci for which sequences were available (act, rpb1, rpb2, tef1; Figs S3-S6; multigene phylogenies Figs 2, S7-S9), with the exception of ITS and LSU where it was not well resolved (Figs 1, S1, S2). The two species can be distinguished based on all individual loci analyzed (Figs S1-S6) and the multigene phylogenies (Figs 2, S7-S9). Multiplex and loop-mediated isothermal amplification (LAMP)-based molecular diagnostics have also recently been described to allow rapid species and mating-type identification of these two Oculimacula species (King et al. 2020).

Rhynchobrunnera B.A. McDonald, U. Braun \& Crous, gen. nov. MycoBank MB838076.

Etymology: Composed of Rhyncho- (from the genus name Rhynchosporium) and Brunner (dedicated to Patrick C. Brunner, 4 July 1962 to 25 September 2019, who shared our passion for cereal fungal pathogens and was always seeking to know more about their origins and how best to define their species boundaries).

Similar to Rhynchosporium, but with different conidial morphology. Conidia solitary, subcylindrical, straight, (0-)1-3-septate, hyaline, hilum neither thickened nor darkened; conidial secession schizolytic.

Type species: Rhynchobrunnera lolii (K.M. King et al.) B.A. McDonald et al.

Ex-holotype culture: CBS $135745=$ IMI 502640.

Rhynchobrunnera lolii (K.M. King et al.) B.A. McDonald, U. Braun \& Crous, comb. nov. MycoBank MB838077. Fig. 6.

Basionym: Rhynchosporium lolii K.M. King et al., PLOS ONE 8: e72536: 13. 2012.

Typus: UK, Shropshire, Newport, diseased leaves of Lolium perenne, May 2011, K.M. King (holotype IMI 502640); culture ex-holotype CBS 135745 = IMI 502640.

Rhynchobrunnera orthospora (Caldwell) B.A. McDonald, U. Braun \& Crous, comb. nov. MycoBank MB838078. Fig. 7. Basionym: Rhynchosporium orthosporum Caldwell, J. Agric. Res., Washington 55: 184. 1937.

Typus: USA, Wisconsin, Whitewater, on Dactylis glomerata, 11 May 1929, R.M. Caldwell (holotype BPI 415280); isotype WIS-f-0049657.

Isolates examined (reference strains): Switzerland, Bäretswil, on leaves of Dactylis glomerata, V.O. Parkinson, CBS 698.79; on leaves of D. 

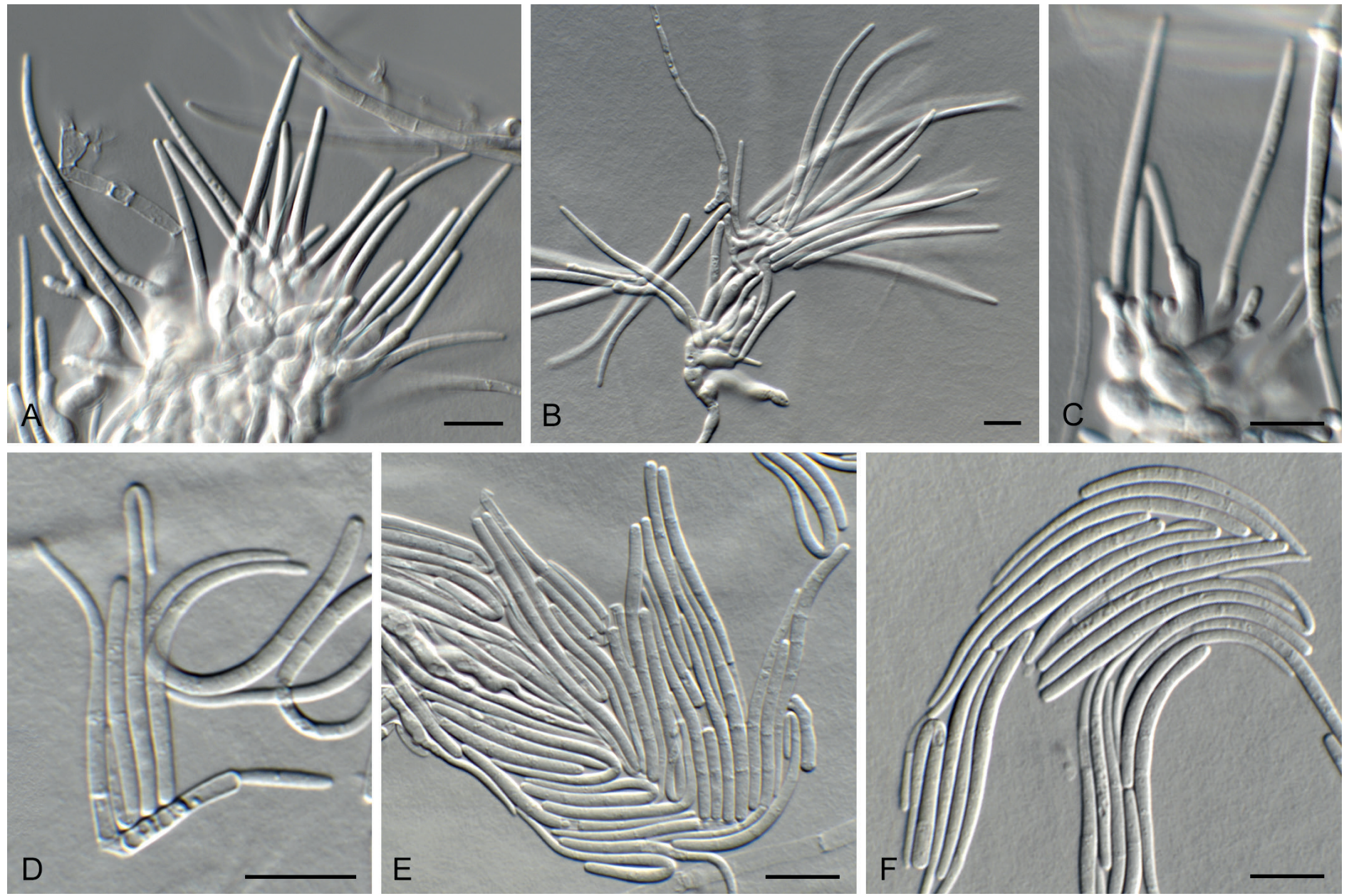

Fig. 5. Oculimacula yallundae (CPC 34945). A-C. Conidiogenous cells giving rise to conidia. D-F. Conidia. Scale bars $=10 \mu \mathrm{m}$.
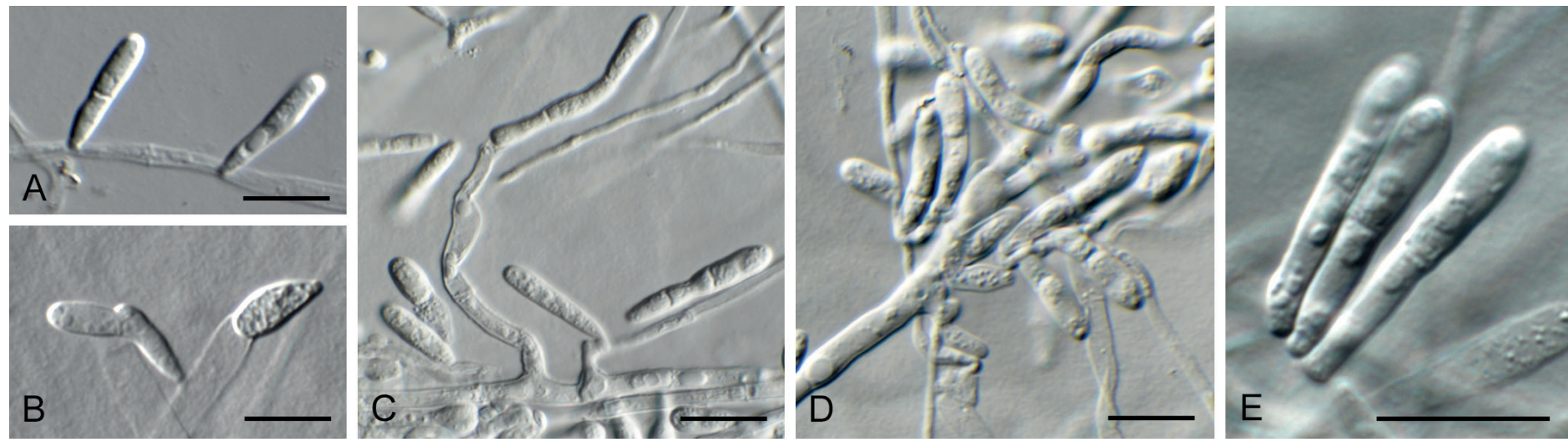

Fig. 6. Rhynchobrunnera lolii (CBS 135745). A-D. Hyphae with conidiogenous cells giving rise to conidia. E. Conidia. Scale bars $=10 \mu \mathrm{m}$.

glomerata, 2004, C.C. Linde, BA2.1.1 = CBS 146767. Italy, Aprica, on leaves of D. glomerata, 2004, C.C. Linde, ITA6.3 = CBS 146768.

Description and illustration of characteristics in vivo: Braun (1995: 256 and 257, fig. 236).

Note: Rhynchobrunnera orthospora was clearly distinguished from the genus Rhynchosporium using more than 380000 genome-wide single nucleotide polymorphisms (SNPs; Mohd-Assaad et al. 2019). However, its distinction from $R$. lolii is controversial based on the analyses of the different gene combinations in the present study. Further studies are required to determine if $R a$. lolii has a wider host range, or if $R a$. orthospora is actually a species complex. Rhynchobrunnera lolii was described by King et al. (2013) based on phylogenetic analyses of nucleotide sequences of the alpha- and beta-tubulin and ITS loci and DNA fingerprinting techniques. Their strain identifications were followed in the present study.

Rhynchosporium Heinsen ex A.B. Frank, Wochenschr. Brauerei 14: 518. 1897.

Mycelium internal, vegetative mycelium sparsely developed, sterile hyphae intraepidermal and in the mesophyll, slender, hyaline, 

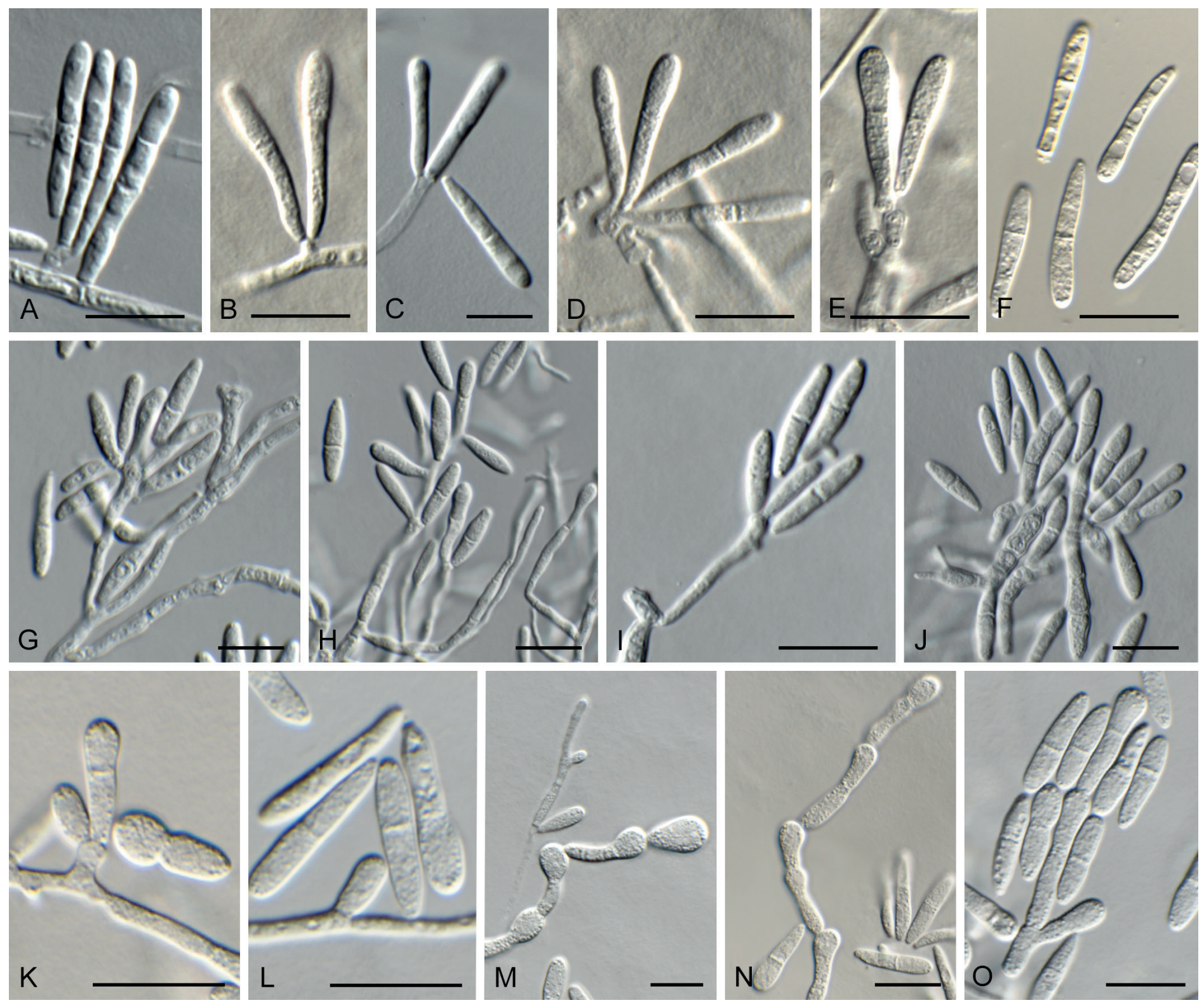

Fig. 7. Rhynchobrunnera orthospora. A-F. (CBS 698.79). A-E. Hyphae with conidiogenous cells giving rise to conidia. F. Conidia. G-J. (CPC 39391). G-I. Hyphae with conidiogenous cells giving rise to conidia. J. Conidia. K-O. (CPC 39392). K-N. Hyphae with conidiogenous cells giving rise to conidia. O. Conidia. Scale bars $=10 \mu \mathrm{m}$.

septate, branched; fertile hyphae subcuticular or immediately below the outer epidermal wall, hyphae horizontally spread, colourless, septate, branched, usually $1.5-5 \mu \mathrm{m}$ wide, often forming ropes of parallel hyphae; single cells, groups of cells or almost all cells of long hyphae are often inflated and form small to moderately large stromatic aggregations; ropes and aggregations are often confluent in severe or old infections and form irregular, diffuse stromatic layers ("pseudo-acervuli"). Integrated, undifferentiated or swollen hyphal cells or particular cells of stromatic hyphal aggregations function as conidiogenous cells, form minute apical peg-like, subcylindrical-conical penetration tubes which perforate the cuticle and produce superficial conidia. Cuticle later often ruptured, stromatic layers erumpent, exposed, superficial. Conidiogenous cells micronematous, monoto polyblastic, percurrent; conidial scars inconspicuous, neither thickened nor darkened. Conidia solitary, subcylindrical, ellipsoidovoid, fusiform, curved or apex abruptly bent (with short oblique apical beak), (0-)1-septate, hyaline, hilum neither thickened nor darkened; conidial secession schizolytic (from Braun 1995).
Type species: Rhynchosporium graminicola Heinsen ex A.B. Frank

Ex-epitype culture: RS99CH6-C1a = ETH ZT Myc2338 = CBS 146761.

Notes: The names Rhynchosporium and $R$. graminicola have often been ascribed to Heinsen. However, these names were validated by Frank (1897). According to Frank (1897), these names were coined by his assistant $\mathrm{E}$. Heinsen, but the validating description, the whole discussion, and even the complete paper were prepared and published by Frank (see Art. 46.2, 46.3; Turland et al. 2018). Rhynchosporium commune and R. agropyri were described by Zaffarano et al. (2011) based on phylogenetic analyses of nucleotide sequences of the alpha- and beta-tubulin genes and PCR-RFLP of the ITS locus. Their strain identifications were followed as references in the present study. 
Rhynchosporium agropyri Zaffarano et al., Mycologia 103: 198. 2011. Fig. 8.

Typus: Switzerland, Zürich, Käferberg, from leaves of Elymus repens (= Agropyron repens), 2004, P. Zaffarano (holotype ZT Myc2337); culture ex-holotype RS04CH-Käferberg-4-1A4.1 = ETH ZT Myc2337 = CBS 146762.

Additional isolates examined: Switzerland, from leaves of E. repens, 2004, P. Zaffarano, K4_5A1 = CBS 146769; from leaves of E. repens, 2005, P. Zaffarano, Daen1.1.2 = CBS 146770.

Notes: Rhynchosporium agropyri was introduced for a species occurring on Agropyron spp., and the apparent paraphyly observed for species of Rhynchobrunnera and Rhynchosporium in for example Figs 2, S1-S9 is most likely due to the fact that the strains were identified using alpha- and beta-tubulin sequences in the original publications (Zaffarano et al. 2011, King et al. 2013), two gene regions not included in the present study.

Rhynchosporium graminicola Heinsen ex A.B. Frank, Wochenschr. Brauerei 14: 518. 1897. Fig. 9.

Synonymy: Ramularia hordei McAlpine, Proc. Linn. Soc. New South Wales 27: 379. 1902.

Rhynchosporium commune Zaffarano, B.A. McDonald \& C.C. Linde, Mycologia 103: 196. 2011.

Typus: Germany, on barley, Frank (1897: 519, unnumbered drawing), lectotype, designated by Braun (2016: 40). Switzerland, Cugy, Canton Vaud, from leaves of Hordeum vulgare, 1999 (epitype designated by Braun (2016: 40), ZT Myc2338); culture ex-epitype, RS99CH6-C1a = ETH ZT Myc2338 = CBS 146761.
Notes: For typification details and discussion of synonymy, see Braun (2016). For additional isolates examined, see Table 1.

Rhynchosporium secalis (Oudem.) Davis, Trans. Wis. Acad. Sci. Arts Lett. 19(2): 713. 1919. Fig. 10.

Basionym: Marssonia secalis Oudem., Med. Kon. Akad. v. Wetensch. 3: 88. 1897.

Typus: Netherlands, on leaves of Secale cereale, R. Bos (holotype missing, not found in L). Switzerland, Reckenholz-Oerlikon, on leaves of Secale cereale, 15 Jun. 1952, E. Müller (neotype CBS 385.52 designated here, MBT394909, preserved as metabolically inactive culture; culture ex-neotype CBS 385.52).

Additional isolates examined: Russia, on leaves of Secale cereale, 2003, P. Zaffarano, RUB2.3 = CBS 146772. Switzerland, $\times$ Triticosecale, 2004, P. Zaffarano, CH4_4b1 = CBS 146771.

Description and illustration of characteristics in vivo: Braun (1995: 255 and 257, fig. 235).

Notes: Rhynchosporium includes several species that cause leaf scald diseases on cereal and grass hosts, and express a high level of host specificity, namely $R$. graminicola (colonising Hordeum glaucum, $H$. leporinum, $H$. murinum, $H$. spontaneum, $H$. vulgare and Bromus diandrus), R. agropyri (Elymus caninus and $E$. repens) and $R$. secalis (Secale cereale and $\times$ Triticosecale) (King et al. 2013). For related species previously treated in Rhynchosporium, see the treatment of Rhynchobrunnera above. Rhynchosporium agropyri, $R$. graminicola and $R$. secalis are phylogenetically very closely related based on the genes used here (Figs 1, 2, S1-S9). The species can be distinguished to some degree based on ITS (Fig. S1). Previous studies have used
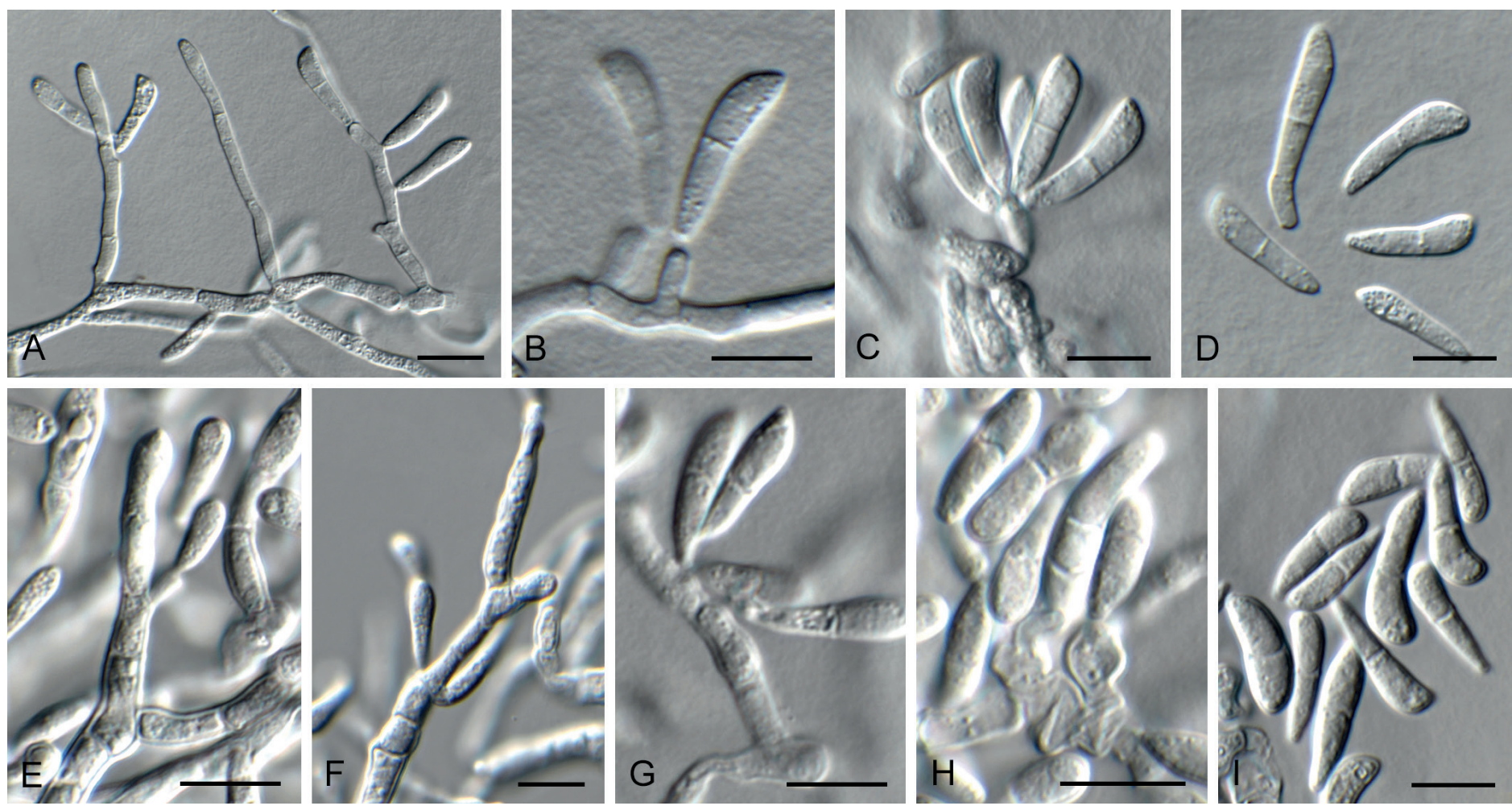

Fig. 8. Rhynchosporium agropyri. A-D. (CPC 39393). A-C. Hyphae with conidiogenous cells giving rise to conidia. D. Conidia. E-I. (CPC 39394). E-H. Hyphae with conidiogenous cells giving rise to conidia. I. Conidia. Scale bars $=10 \mu \mathrm{m}$. 
RAPDs and species-specific PCR diagnostic tests (e.g. King et al. 2013) or a combination of alpha-tubulin, beta-tubulin and ITS sequences for species delimitation (Zaffarano et al. 2008, 2011). More recent studies used approximately 380000 genome-wide SNPs to confirm species boundaries (Mohd-Assaad et al. 2019).

\section{Septogloeum Sacc., Michelia 2: 11. 1880.}

Mycelium immersed, branched, septate, hyaline. Conidiomata acervular, epidermal to subepidermal, separate or confluent, formed of pale brown thin-walled pseudoparenchyma. Dehiscence irregular. Conidiophores short, stout, 1-2-septate,
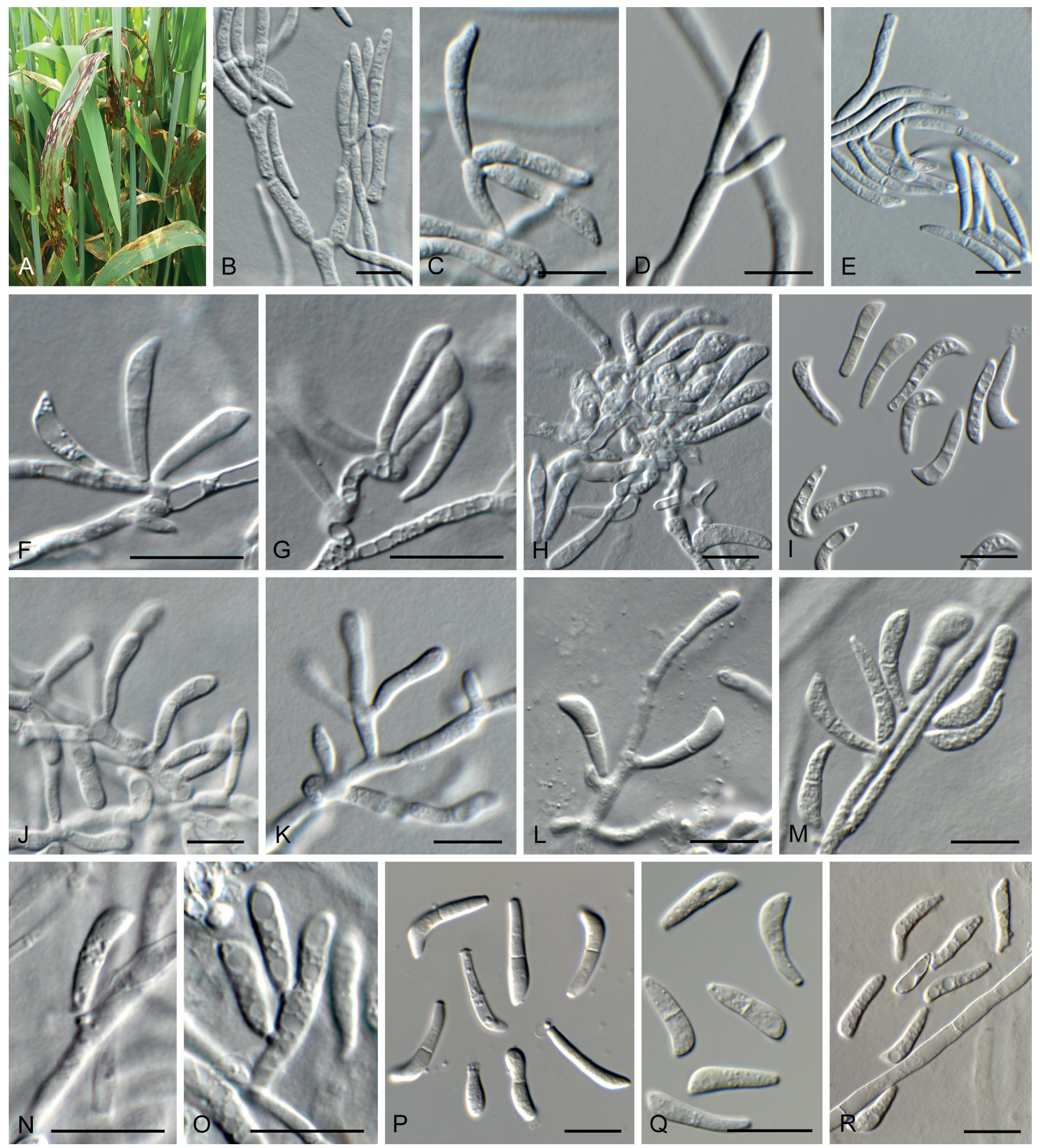

Fig. 9. Rhynchosporium graminicola. A. Disease symptoms on Hordeum vulgaris. B-E. (CPC 39388). B-D. Hyphae with clusters of conidiogenous cells giving rise to conidia. E. Conidia. F-I. (CBS 135932). F-H. Hyphae with conidiogenous cells giving rise to conidia. I. Conidia. J-M. (CBS 483.50). J-L. Hyphae with conidiogenous cells giving rise to conidia. M. Conidia. N-R. (CBS 385.52). N-Q. Hyphae with conidiogenous cells giving rise to conidia. R. Conidia. Scale bars $=10 \mu \mathrm{m}$. 

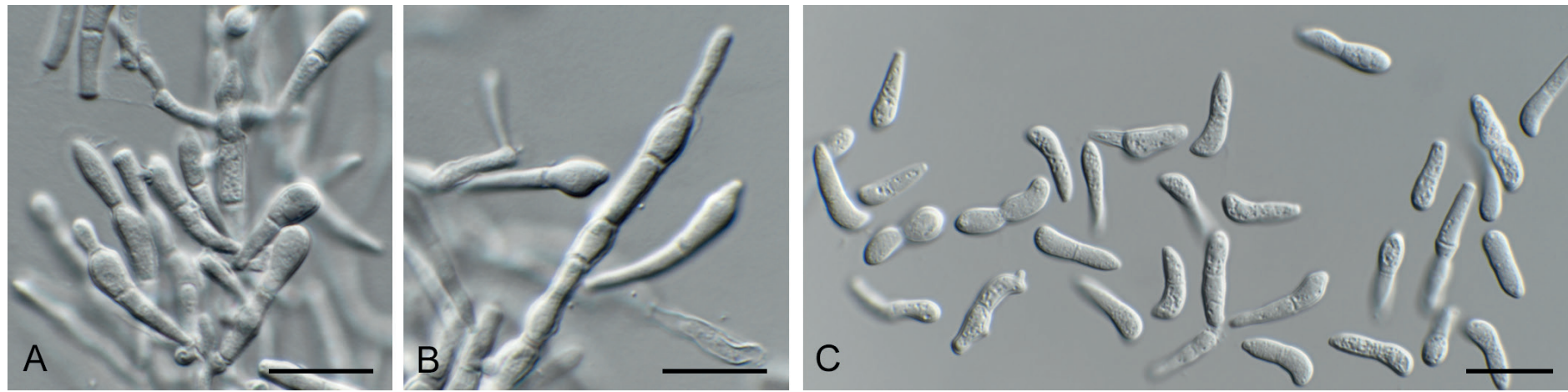

Fig. 10. Rhynchosporium secalis (CPC 39385). A, B. Hyphae with conidiogenous cells giving rise to conidia. C. Conidia. Scale bars $=10 \mu \mathrm{m}$.

hyaline, smooth, branched at the base, formed from the upper pseudoparenchyma. Conidiogenous cells enteroblastic, phialidic, discrete or integrated, determinate, cylindrical, doliiform to obpyriform, hyaline, smooth, channel wide, collarette minimal, periclinal wall thickened. Conidia hyaline, 1-3-euseptate, thinwalled, smooth, eguttulate, base truncate, apex obtuse, straight or curved, constricted, obovoid (from Sutton 1980).

Type species: S. carthusianum (Sacc.) Sacc.

Ex-type culture: No culture avaialble.

Notes: Although some of the isolates from cereals studied here were formerly identified as species of Septogloeum, Sutton \& Pollack (1974) restricted the genus Septogloeum to two species, S. carthusianum and S. thomasianum. DNA data of the type species (on Euonymus europaeus, Europe) need to be obtained to facilitate a revision of Septogloeum.

\section{Spermospora R. Sprague, Mycologia 40: 177. 1948.}

Mycelium internal, hyphae hyaline, septate, branched, slender, forming solitary to aggregated (sometimes stromatic) swollen vesicular intraepidermal, sometimes substomatal cells, shape and size variable, hyaline. Most of these vesicles functioning as conidiogenous cells ("mother cells"), conical to ampulliform, apically attenuated, forming minute, narrow penetration tubes which perforate the cuticle of the host plant or emerge through the stomatal opening; two or even more penetration tubes may occasionally be formed from a single vesicle or minute tubes arise from narrow, hardly differentiated hyphal cells; penetration tubes or attenuated apical parts of conidiogenous cells bearing a single terminal, holoblastic conidium; penetration tubes sometimes becoming inflated above the host surface and forming a single or rarely two conidia; conidial scars inconspicuous, neither thickened nor darkened. Macroconidia solitary, scolecosporous, acicular-fusiform, obclavate, straight to curved, hyaline, euseptate, smooth, usually tapering towards the apex, basal cells sometimes with a short lateral or sub-basal narrow appendage, hilum more or less truncate, unthickened, hyaline; conidial secession schizolytic (from Braun 1995). Microconidia subcylindrical, hyaline, smooth, 0(-1)-septate, base truncate, apex obtuse, straight.

\section{Type species: Spermospora subulata (R. Sprague) R. Sprague}

Typus: USA, Oregon, Main Divide Trail, Ochoco Nat. Forest, on Melica subulata, 21 Aug. 1916, Ingram 606 (holotype OSC 10.669); isotypes BPI 420956, FH 01012456, NY 01042813. No culture available.

Notes: As treated here, the genus Spermospora is paraphyletic, awaiting the recollection of the type species, Sp. subulata. Although we suspect that $S p$. subulata would be allied to $S p$. ciliata and Sp. zeae (Spermospora s.str.), this remains to be elucidated.

Spermospora arrhenatheri Crous, sp. nov. MycoBank MB838079. Fig. 11.

Etymology: Name refers to the genus Arrhenatherum, to which the host of this species belongs.
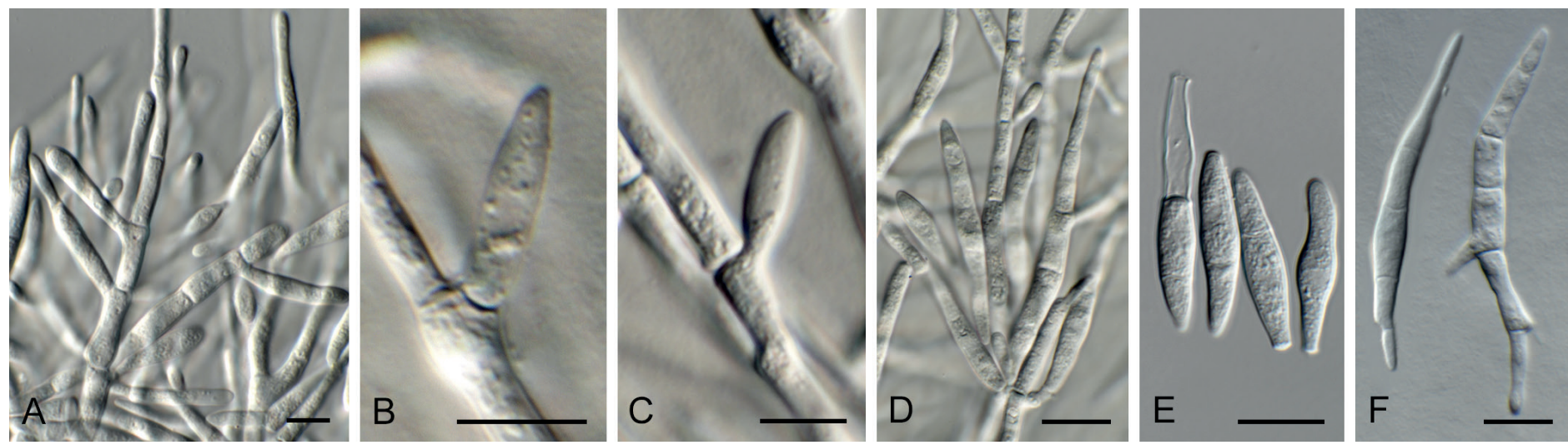

Fig. 11. Spermospora arrhenatheri (CBS 320.68). A-D. Hyphae with conidiogenous cells giving rise to conidia. E, F. Conidia. Scale bars $=10 \mu \mathrm{m}$. 
Conidiophores mostly reduced, $2 \mu \mathrm{m}$ diam, conidiogenous loci formed directly on hyphae. Conidia hyaline, smooth, granular, (2-)3(-4)-septate, fusoid to fusoid-obclavate, (30-)40-50(-60) $\times(4-) 5-6 \mu \mathrm{m}$; basal appendage arising above the hilum, lateral, pointing downwards, at times appearing as a germ tube with a septum separating it from the conidium body, 5-15 $\times 2 \mu \mathrm{m}$, developing while still attached to the conidiogenous cell.

Typus: Germany, Kiel-Kitzeberg, on Arrhenatherum elatius, Jul. 1966, U.G. Schlösser, No. 16 (holotype CBS 320.68, preserved as metabolically inactive culture; culture ex-holotype CBS 320.68).

Notes: The culture of Sp. arrhenatheri was originally deposited as Septogloeum oxysporum (now Cheilaria agrostidis), a fungus causing blotch and tar spot of various grasses (conidiomata acervular, conidia hyaline, 1-3-septate, obovoid; Mäkelä \& Koponen 1976, Sutton 1980), which is quite different from the fungus treated here. The species formed a single-strain lineage for most of the loci for which a sequence was available (ITS, act, rpb2; Figs S1, S3, S5; multigene phylogenies Figs 2, S7-S9), with the exception of LSU where it was not well resolved (Figs 1, S2).

Spermospora ciliata (R. Sprague) Deighton, Trans. Br. mycol. Soc. 51: 44. 1968. Figs 12, 13.

Basionym: Spermospora subulata f. ciliata R. Sprague, Mycologia 41: 495. 1949.
Mycelium of hyaline, smooth, branched, septate, 2-4 um diam hyphae. Conidiophores reduced to hyphae forming conidiogenous loci, or solitary, erect, hyaline, smooth, subcylindrical, 0-2-septate, 10-20 × 2.5-3.5 $\mu \mathrm{m}$. Conidiogenous cells terminal, integrated, subcylindrical, 5-10 × 2.5-3 $\mu \mathrm{m}$; proliferating sympodially. Conidia solitary, hyaline, smooth, guttulate, fusoid to fusoid-obclavate, straight to curved, apical cell forming a flexuous appendage, 1-2(-3)-septate, (20-)30$40(-47) \times(2.5-) 3 \mu \mathrm{m}$; apical cell (incl. flexuous appendage) 11$25 \mu \mathrm{m}$ long, base truncate, 1.5-2 $\mu \mathrm{m}$ diam, not thickened nor darkened (CBS 135.38).

Conidia solitary, hyaline, smooth, guttulate, fusoid, rarely fusoidobclavate, straight to curved, apical cell forming a flexuous appendage, 1-2(-3)-septate, (20-)37-50(-65) × 3-3.5(-4) $\mu \mathrm{m}$; apical cell (incl. flexuous appendage) 17-45 $\mu \mathrm{m}$ long, base truncate, 1.5-2 $\mu \mathrm{m}$ diam, not thickened nor darkened; basal appendage arising laterally, above the basal hilum, at times separated by a septum (CBS 287.69).

Conidiophores mostly reduced to loci occurring directly on hyphae, $2 \mu \mathrm{m}$ diam. Conidia hyaline, smooth, fusoid to obclavatefusoid, 3(-4)-septate, (33-)35-60(-80) × 3(-3.5) $\mu \mathrm{m}$, apical cell (incl. flexuous appendage) (20-)30-55 $\mu \mathrm{m}$ long (CBS 316.68).

Typus: USA, Wyoming, Teton Pass, on Agrostis stolonifera, 13 Aug. 1948, Sprague et al. (holotype WSP 20123).
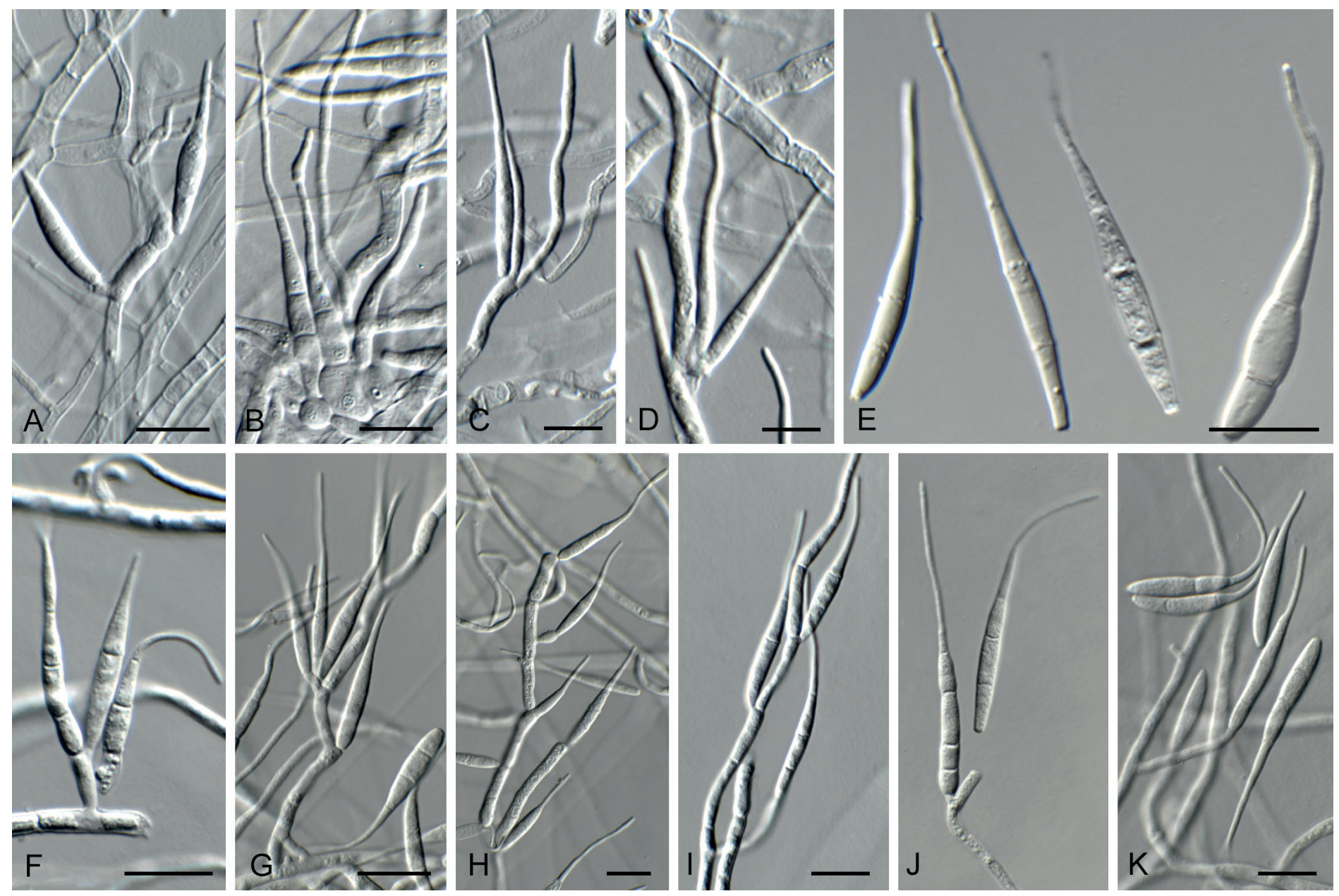

Fig. 12. Spermospora ciliata. A-E. (CBS 135.38). A-D. Hyphae with conidiogenous cells giving rise to conidia. E. Conidia. F-K. (CBS 316.68). F-J. Hyphae with conidiogenous cells giving rise to conidia. $\mathrm{K}$. Conidia. Scale bars $=10 \mu \mathrm{m}$. 

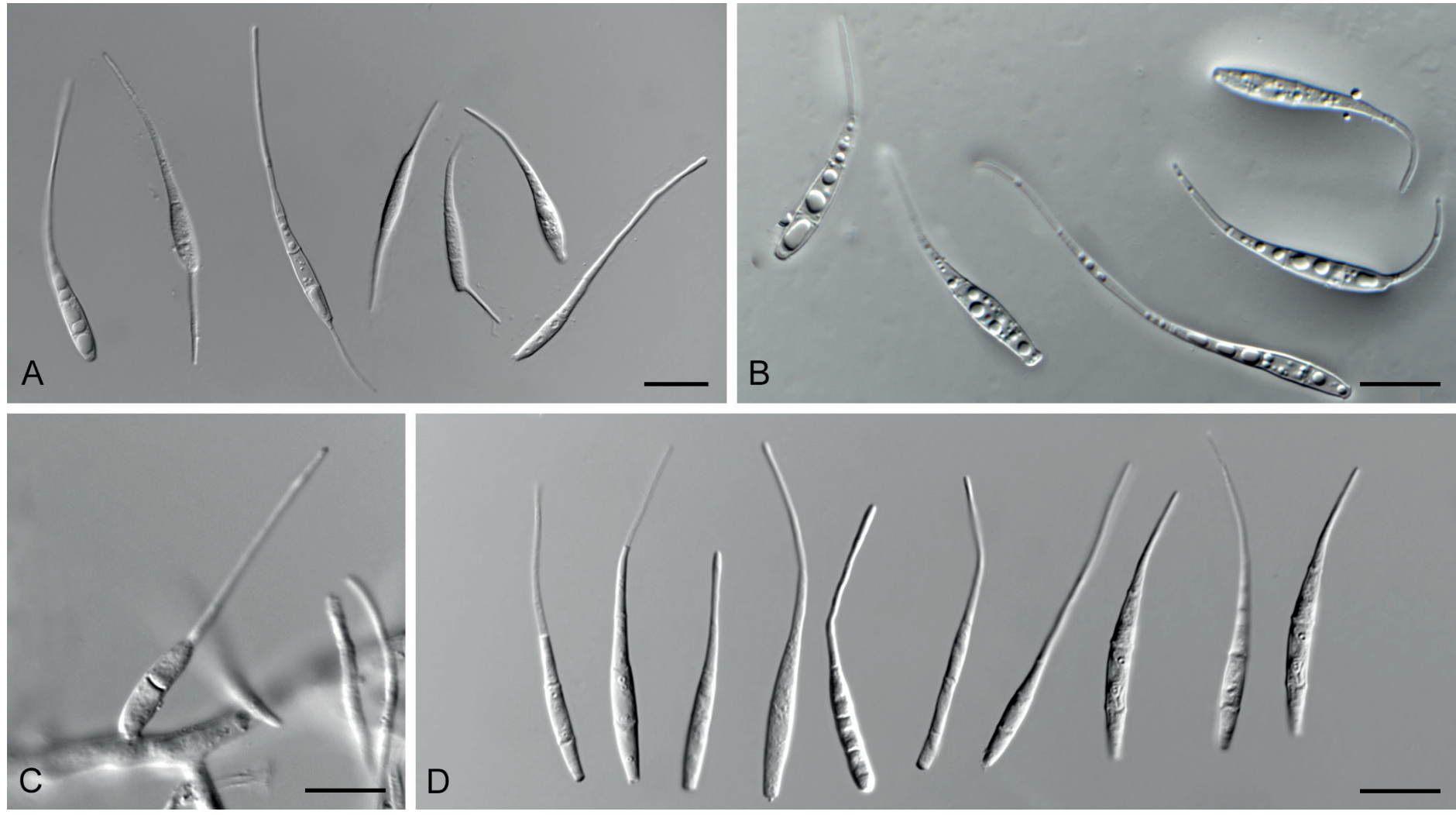

Fig. 13. Spermospora ciliata (CBS 285.69). A, B. Conidia (CBS 287.69). C. Conidium developing on conidiogenous locus. D. Conidia (CBS 285.69). Scale bars $=10 \mu \mathrm{m}$.

Isolates examined: Germany, Kiel-Kitzeberg, on Festuca arundinacea, U.G. Schlösser, No. 54, May 1967, CBS 285.69; Kr. Plön, Mönkeberg, on Festuca heterophylla, U.G. Schlösser, No. 85, Aug. 1967, CBS 287.69; Kiel-Kitzeberg, on Festuca rubra, May 1967, U.G. Schlösser, No. 59, culture CBS 316.68. USA, Oregon, Halsey, on Festuca rubra, 1937, R. Sprague, OSC 10669, CBS 135.38.

Description and illustration of characteristics in vivo: Braun (1995: 242, fig. 224 and 243).

Notes: The genus Spermospora is similar to Rhynchosporium in that it also has immersed, swollen conidiogenous cells with minute tubes that penetrate the cuticle and bear solitary nonscolecosporous conidia (Braun 1995). The type species, $S$. subulata, has narrow conidia, with those in the holotype being obclavate, 1-2(-4)-septate, (15-)20-30(-65) × 3-4.5 $\mu \mathrm{m}$ (Braun 1995).

Isolate CBS 135.38 was deposited by R. Sprague in 1937 as S. subulata (on Festuca rubra, in Halsey, Oregon). However, a few years later, Sprague described S. subulata f. ciliata, which was later elevated to species level as $S$. ciliata. Conidia of $S$. ciliata (on Agrostis alba, Wyoming, USA) are reported to be fusoid to obclavate-fusoid, $20-75 \times(2-) 3-6(-8) \mu \mathrm{m}, 2-4$-septate; apical cell with appendage 5-35 $\mu \mathrm{m}$ long, with lateral filiform appendage $5 \mu \mathrm{m}$ long (Braun 1995). Isolate CBS 135.38 is thus more appropriately placed in S. ciliata than S. subulata. Braun (1995) was of the opinion that S. subulata should be confined to species occurring on Melica in the USA, having narrowly obclavate, 1-2-septate conidia, and that isolates from other hosts probably belonged to S. ciliata (conidia fusoid to obclavatefusoid, 2-4-septate, the basal cell occasionally having a narrow, lateral, filiform appendage). Isolates of S. ciliata formed a fully or highly supported sister lineage to $S$. zeae in analyses of most of the loci for which sequences were available (ITS, act, rpb1, rpb2, tef1; Figs S1, S3-S6; multigene phylogenies Figs 2, S7-S9).

Spermospora Ioliiphila Crous, sp. nov. MycoBank MB838080. Fig. 14.

Etymology: Name composed of Lolium, to which the host of this species belongs, and -philus (-loving).

Mycelium consisting of hyaline, smooth, branched, septate, 2-4 $\mu \mathrm{m}$ diam hyphae. Species dimorphic. Microconidial morph: Microconidiophores reduced to microconidiogenous cells or loci formed directly on hyphae, or erect, subcylindrical, 5-15 $\times$ 2-3 $\mu \mathrm{m}$, proliferating sympodially, giving rise to mucoid conidial masses. Microconidia subcylindrical, hyaline, smooth, $0(-1)$-septate, base truncate, apex obtuse, straight, (8-)10-13(17) $\times 2 \mu \mathrm{m}$. Macroconidiophores subcylindrical, hyaline, smooth, 0-2-septate, unbranched, 10-20 × 2-3 $\mu \mathrm{m}$. Macroconidiogenous cells integrated, hyaline, smooth, 5-10 $\times 2-3 \mu \mathrm{m}$, proliferating sympodially. Macroconidia hyaline, smooth, guttulate, fusoid straight to slightly curved, 3(-5)-septate, (25-)35-55(-65) × 3(-4) $\mu \mathrm{m}$; apical cell (incl. flexuous apical appendage) 10-20 $\mu \mathrm{m}$ long.

Typus: New Zealand, Palmerston North, on Lolium perenne, Aug. 1964, U.G. Schlösser, No. 124 (holotype CBS 286.69, preserved as metabolically inactive culture; culture ex-holotype CBS 286.69).

Notes: Isolate CBS 286.69 (from Lolium perenne, New Zealand), was deposited as S. subulata [conidia obclavate, 1-2(-4)-septate, $(15-) 20-30(-65) \times 3-4.5 \mu \mathrm{m}$; Braun 1995]. It differs from $S$. subulata in having fusoid macroconidia, and a microconidial morph with aseptate conidia, and from S. ciliata [conidia fusoid 

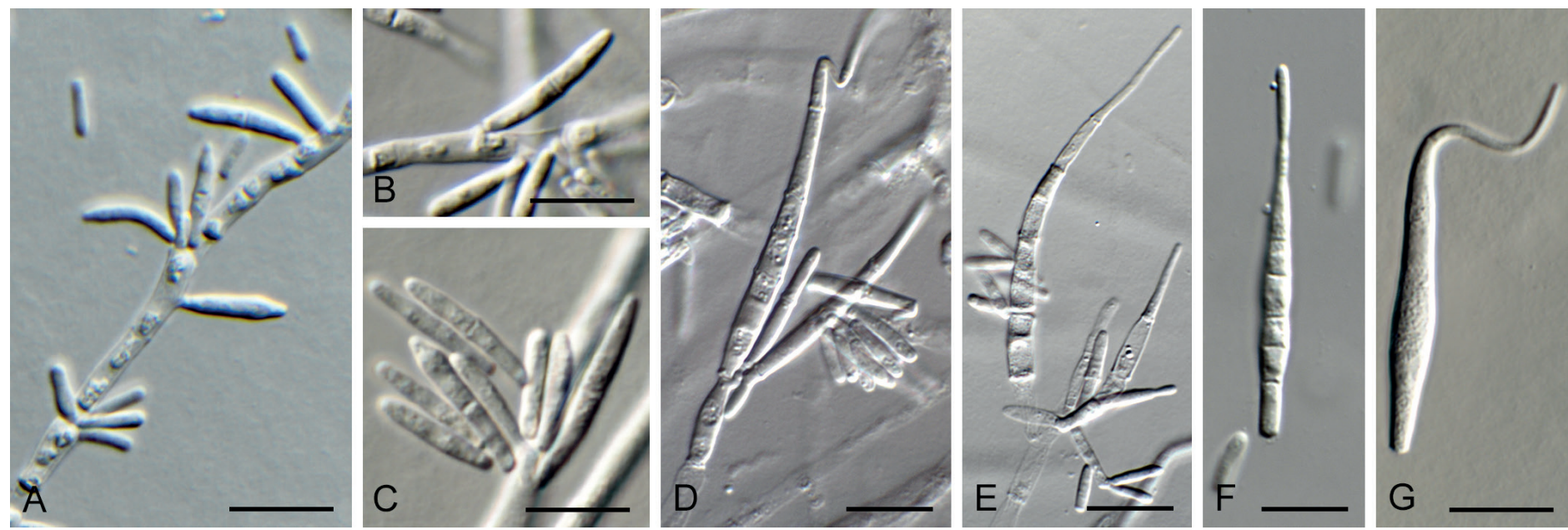

Fig. 14. Spermospora loliiphila (CBS 286.69). A. Hyphae with conidiogenous loci giving rise to microconidia. B, C. Microconidia. D, E. Macro- and microconidia. F, G. Macroconidia. Scale bars $=10 \mu \mathrm{m}$.

to obclavate-fusoid, 2-4-septate, 20-75 × (2-)3-6(-8) $\mu \mathrm{m}$; Braun 1995] in having narrower macroconidia and a microconidial morph. Furthermore, it differs from S. Iolii (from Lolium perenne, Ireland; conidia fusoid to obclavate-fusoid, 2-7-septate, 35-70 x 3.5-4.5 $\mu \mathrm{m}$; Braun 1995) based on its smaller macroconidia with less septa. The species formed a single-strain lineage for most of the loci for which a sequence was available (ITS, act, rpb2, tef1; Figs S1, S3, S5, S6; multigene phylogenies Figs 2, S7-S9), with the exception of LSU where it was not well resolved (Figs 1, S2). In the ITS phylogeny (Fig. S1), it is basal to Spermospora zeae and S. ciliata with a low posterior probability value. It does not form a monophyletic group with Spermospora zeae and $S$. ciliata based on act (Fig. S3), rpb2 (Fig. S5), tef1 (Fig. S6) and could represent a cryptic genus in this complex.

Spermospora zeae Crous, sp. nov. MycoBank MB838081. Fig. 15.

Etymology: Name refers to the genus Zea, from which this species was isolated.

Mycelium consisting of hyaline, smooth, septate, branched, 2.5$3 \mu \mathrm{m}$ diam hyphae. Conidiophores reduced to conidiogenous cells or solitary loci, erect, subcylindrical, hyaline, smooth, 0-1-septate, unbranched, 10-25 × 2-3 $\mu \mathrm{m}$. Conidiogenous cells terminal, integrated, subcylindrical, smooth, hyaline, 8-10 $\times 2-3 \mu \mathrm{m}$, proliferating sympodially. Conidia aggregating in mucoid clusters, fusoid to obclavate-fusoid, hyaline, smooth, guttulate, (0-)3-septate with truncate hilum, $2 \mu \mathrm{m}$ diam, and apex tapering to a long flexuous apical appendage terminating in subobtuse end, (25-)30-40(-45) × (2.5-)3(-4) $\mu \mathrm{m}$; apical cell (incl. appendage) (7-)15-22 $\mu \mathrm{m}$ long; basal appendage aseptate, cellular, lateral, pointing downwards, arising just above basal hilum, at times appearing as a germ tube from the basal hilum. Older conidia undergoing microcyclic conidiation, with conidia developing several lateral appendages, also arising from central cells of the conidium body, and the apical appendage can even branch dichotomously.

Typus: Switzerland, Zürich, endophyte in Zea mays, E. Müller ETH 8867 (holotype CBS 306.79, preserved as metabolically inactive culture; culture ex-holotype CBS 306.79).

Note: Spermospora zeae formed a single-strain lineage sister to Spermospora ciliata for most of the loci for which a sequence was available (ITS, act, rpb2; Figs S1, S3, S5; multigene phylogenies
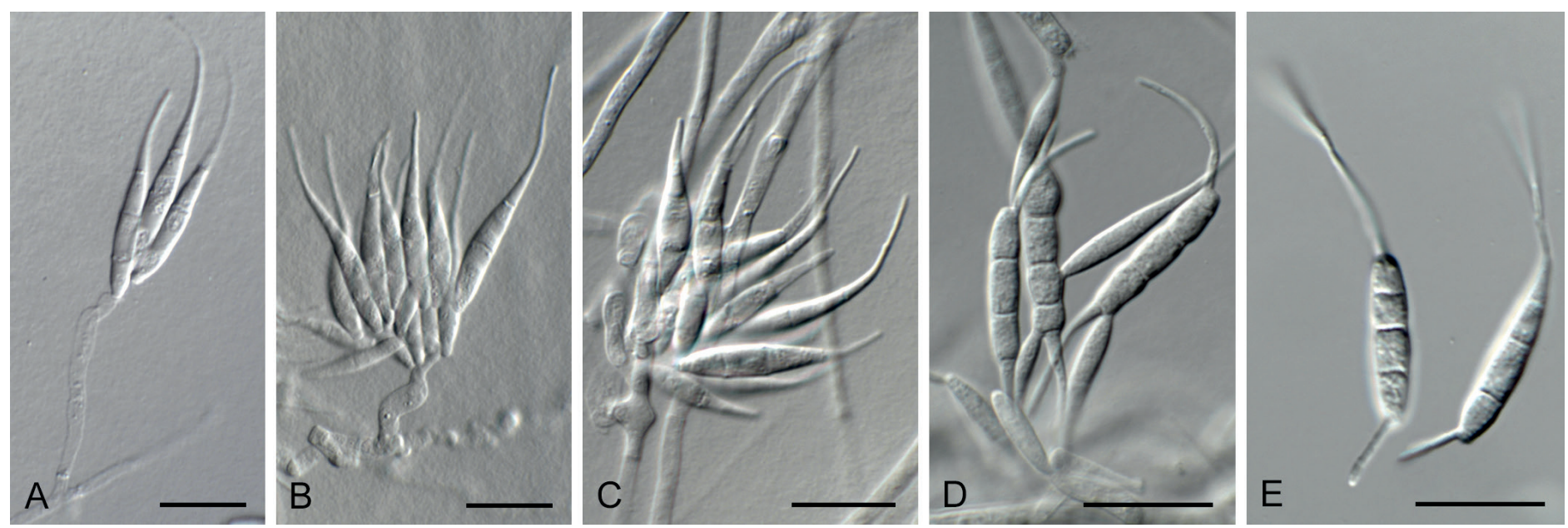

Fig. 15. Spermospora zeae (CBS 306.79). A-D. Hyphae with conidiogenous cells giving rise to conidia. E. Conidia. Scale bars $=10 \mu \mathrm{m}$. 
Figs 2, S7-S9), with the exception of LSU where it was not well resolved (Figs 1, S2).

Vanderaaea Crous, gen. nov. MycoBank MB838082.

Etymology: Named in honour of the Dutch mycologist Hubertus Antonius "Huub" van der Aa (5 July 1935 - 7 May 2017), who was a mycologist dealing with coelomycetous fungi at the "Centraalbureau voor Schimmelcultures", and also collected and isolated this fungus.

Conidiomata sporodochial, round, erumpent, green-brown, giving rise to a mucoid conidial mass. Conidiophores reduced to conidiogenous cells formed on a stroma of pale brown pseudoparenchymatal cells, smooth, ampulliform to subglobose, proliferating holoblastically. Conidia solitary, hyaline, smooth, 0-1-septate, fusoid, flexuously curved, apical cell developing into a long flexuous apical appendage with subobtuse tip, basal cell tapering towards a truncate hilum.

\section{Type species: Vanderaaea ammophilae Crous}

Vanderaaea ammophilae Crous, sp. nov. MycoBank MB838083. Fig. 16.

Etymology: Name reflects Ammophila, the host genus it was collected from.

Conidiomata up to $350 \mu \mathrm{m}$ diam, sporodochial, round, erumpent, green-brown, giving rise to a mucoid conidial mass. Conidiophores reduced to conidiogenous cells, pale brown, smooth, ampulliform to subglobose, 4-6 $\times 2-3 \mu \mathrm{m}$, proliferating holoblastically. Conidia solitary, hyaline, smooth, 0-1-septate, septum submedian, fusoid, flexuously curved, apical cell developing into a long flexuous apical appendage with subobtuse tip, basal cell tapering towards truncate hilum, $1 \mu \mathrm{m}$ diam; conidia (20-)21-22(-24) × (1.5-)2 $\mu \mathrm{m}$, apical cell 11-14 $\mu \mathrm{m}$ long, basal cell 7-10 $\mu \mathrm{m}$ long.

Typus: Netherlands, Texel, "De Krim", on dead leaves of Ammophila arenaria, 26 Oct 1968, H.A. van der Aa (holotype CBS H-18325; culture ex-holotype CBS 886.68).

Notes: Isolate CBS 886.68 was originally identified as Spermospora avenae, but is quite distinct in having sporodochial conidiomata, and 0-1-septate, flexuously curved conidia. The species is distinct from all species treated here as belonging to Acarosporales (Lecanoromycetes) by forming sporodochia with curved, 0-1-septate conidia (Fig. 1, part 1).

Ypsilina J. Webster et al., Canad. J. Bot. 76: 1658. 1999.

Conidiophores terminal, simple or branched, hyaline, septate. Conidiogenous cells terminal, proliferating sympodially or percurrently at the apex. Conidia Y-shaped, terminal, single, variously branched, with arms long-conoid, septate, with acute apices, bases truncate, or with a subulate basal extension; branches sequential, opposite, alternate, dorsal. Synasexual morph phialidic, forming hyaline, aseptate conidia.

Type species: Ypsilina graminea (Ingold et al.) Descals et al.

\section{Ex-epitype culture: CBS 114630.}

Ypsilina graminea (Ingold et al.) Descals et al., Canad. J. Bot. 76: 1659. 1999 (1998). Fig. 17.

Basionym: Volucrispora graminea Ingold et al., Trans. Brit. Mycol. Soc. 51: 325. 1968.

Typus: UK, England, county of Cumbria (former Cumberland), Aira Force, undated, isolated from freshwater foam (holotype IMI 123908); UK, on roots of Triticum aestivum, 10 Nov. 2001, H. Kwasna (epitype designated here CBS 114630, MBT394914, preserved as metabolically inactive culture; culture ex-epitype CBS 114630).

Additional cultures examined: Antarctica, King George, Jubany, on a leaf of Deschampsia antarctica, 1991, C. Möller, No. 17/10, CBS 691.92; King George, Arctowski, on a lichen, 1991, C. Möller, No. 42/10, CBS 692.92. Germany, Kr. Husum, Hollingstedt, on Holcus lanatus, U.G. Schlösser, No. 231, CBS 895.72.

Notes: The species has been isolated from freshwater foam in the UK, but also from grass leaves and roots of Triticum aestivum and Holcus lanatus, and as shown here, from a lichen in Antarctica. However, its ecology remains largely unknown (Descals et al. 1998). Ypsilina graminea formed a fully or highly supported lineage in the analyses of most of the loci for which sequences were available (ITS, act, rpb1, rpb2, tef1; Figs S1, S3S6; multigene phylogenies Figs 2, S7-S9), with the exception of
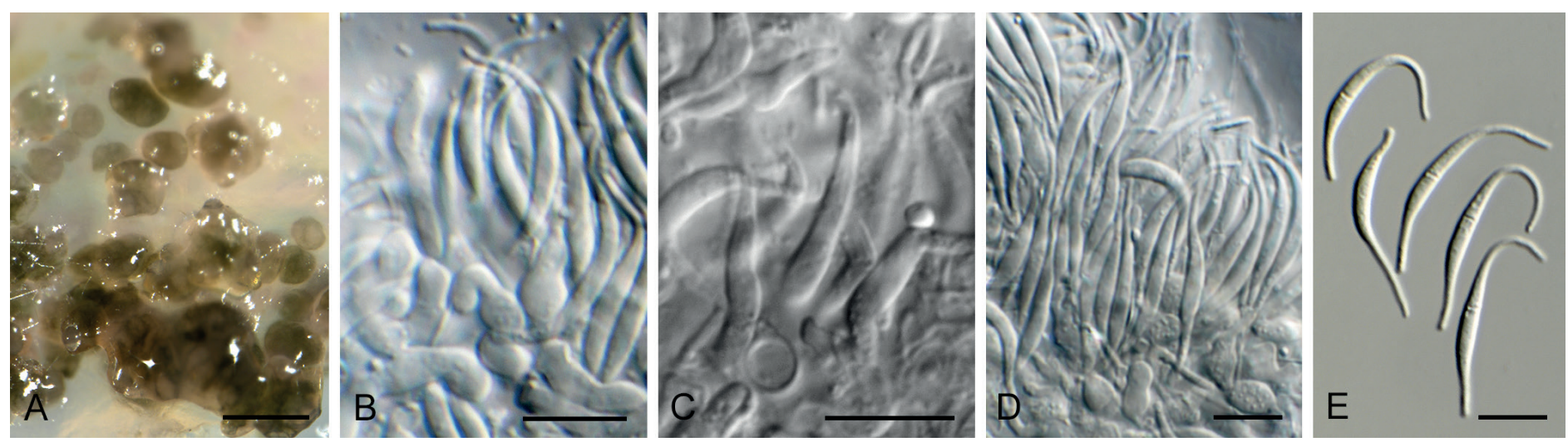

Fig. 16. Vanderaaea ammophilae (CBS 886.68). A. Sporulating colony on oatmeal agar. B-D. Conidiogenous cells giving rise to conidia. E. Conidia. Scale bars $=10 \mu \mathrm{m}$. 

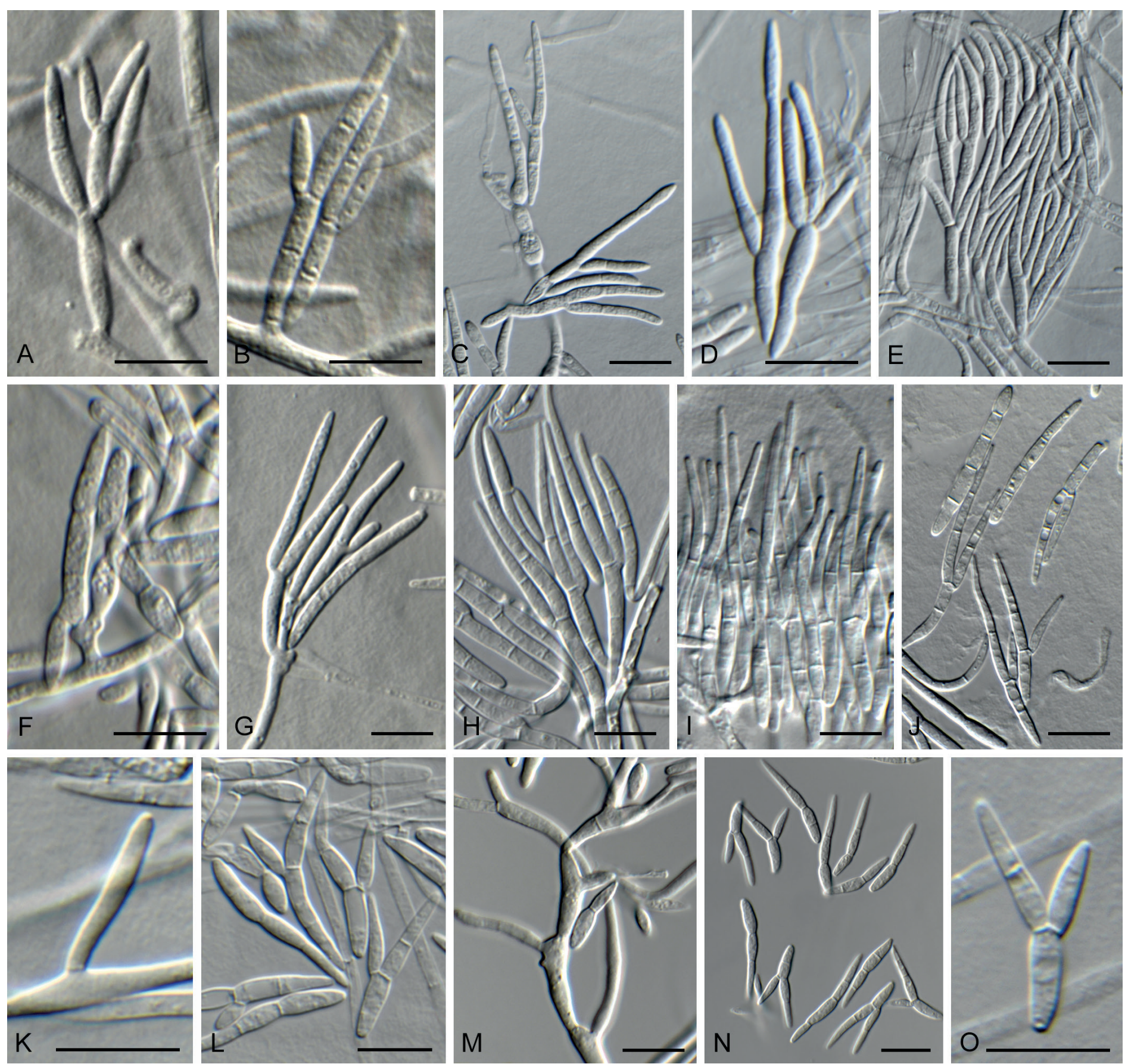

Fig. 17. Ypsilina graminea. A-E. (CBS 691.92) A-C. Hyphae with conidiogenous cells giving rise to conidia. D, E. Conidia. F-J. (CBS 692.92). F-H. Hyphae with conidiogenous cells giving rise to conidia. I, J. Conidia. K-O. (CBS 114630). K-M. Hyphae with conidiogenous cells giving rise to conidia. N, O. Conidia. Scale bars $=10 \mu \mathrm{m}$.

LSU where it was not well resolved (Figs 1, S2). Some intraspecific variation exists for this species: in ITS up to five substitutions and one indel, in act up to eight substitutions and one indel; in rpb1 up to 17 substitutions; in rpb2 up to 49 substitutions. The similarity of the tef1 sequences of the ex-type strain ranges from $90 \%$ (CBS 895.72) to $83 \%$ (CBS 692.92), whereas the LSU sequences of the four analysed strains were identical.

\section{DISCUSSION}

The present study aimed to resolve the status of genera for the well-known cereal pathogens Oculimacula, Rhynchosporium and Spermospora. In the process, we had to consider the genera Septogloeum and Ypsilina, which were found to be phylogenetically related.

The phylogenetic and morphological differences among species of Rhynchosporium (leaf blotch of cereals) have been well documented in papers dealing with these taxa (Zaffarano et al. 2011, King et al. 2013, Zaveri et al. 2020), and thus it is not totally surprising that the genus Rhynchobrunnera had to be introduced to accommodate species that have 1-3-septate, straight conidia lacking apical beaks, in contrast to 1-septate conidia with hooked apical beaks in Rhynchosporium as delimited here. Furthermore, although Rhynchosporium commune was coined as a name for the barley scald pathogen (Zaffarano et al. 2011), Braun (2016) showed that R. graminicola, the type species of the genus, represented an older name for this taxon. 
Rhynchosporium commune should thus be treated as synonym of $R$. graminicola.

Although species of Oculimacula (eyespot disease of cereals) have been well studied in the past (Nirenberg 1981), their generic circumscription (Crous et al. 2003) relied mainly on ribosomal gene phylogenies (ITS/LSU), which suggested four species to be accommodated in the genus. Of these, only two form typical Oculimacula apothecia, and are retained as $O$. acuformis and $O$. yallundae. Helgardiomyces is introduced as a new genus based on $H$. anguioides, characterised by having fast-growing cultures with long, flexuous, subcylindrical, pluriseptate conidia, while Pseudocercosporella aestiva is placed in Cyphellophora, based on its conidiogenous cells with flared phialides, which frequently develop directly on fungal hyphae.

Of all the genera treated here, Spermospora proved to be morphologically the most challenging, here segregated into two genera. Neospermospora gen. nov. is introduced for S. avenae, in addition to three new species of Spermospora, S. arrhenatheri, $S$. loliiphila and $S$. zeae. However, the species retained in Spermospora formed a paraphyletic group that warrants further studies, a matter that can only be resolved once fresh collections of the type species, S. subulata have been obtained.

Other genera that were considered either because they were phylogenetically related, or isolates were incorrectly identified under these names, include Vanderaaea and Ypsilina. Ypsilina (type: Y. graminea), occurs on various substrates, including roots and leaves of cereals, but appears to be of minor phytopathological importance. Vanderaaea gen. nov. (type: V. ammophilae), is a coelomycetous fungus occurring on dead leaves of Ammophila arenaria. Finally, the genus Septogloeum, which is a name that has been tentatively applied to some cereal fungi in the past, remains presently unresolved, pending further collections and acquisition of DNA data.

\section{ACKNOWLEDGEMENTS}

We are grateful to Matthew Kokolski (University of Nottingham) for help in culture preparation and the BBSRC (UK) for research funding (PSD). We also thank Arien van Iperen (cultures), Mieke Starink-Willemse (DNA isolation, amplification, and sequencing), and Marjan Vermaas (photographic plates) for their technical assistance (Westerdijk Fungal Biodiversity Institute).

Conflict of interest: The authors declare that there is no conflict of interest.

\section{REFERENCES}

Avrova A, Knogge W (2012). Rhynchosporium commune: a persistent threat to barley cultivation. Molecular Plant Pathology 13: 986-997. Bateman GL (1988). Pseudocercosporella anguioides, a weakly pathogenic fungus associated with eyespot in winter wheat at a site in England. Plant Pathology 37: 291-296.

Braun U (1995). A monograph of Cercosporella, Ramularia and allied genera (Phytopathogenic Hyphomycetes). Vol. 1. IHW-Verlag, Eching.

Braun U (2016). Rhynchosporium graminicola revisited and reinstated. Schlechtendalia 30: 39-40.
Braun U, Nakashima C, Crous PW, et al. (2018). Phylogeny and taxonomy of the genus Tubakia s. lat. Fungal Systematics and Evolution 1: 41-99.

Crous PW, Braun U, Wingfield MJ, et al. (2009). Phylogeny and taxonomy of obscure genera of microfungi. Persoonia 22: 139-161.

Crous PW, Gams W, Stalpers JA, et al. (2004). MycoBank: an online initiative to launch mycology into the 21st century. Studies in Mycology 50: 19-22.

Crous PW, Groenewald JZ, Gams W (2003). Eyespot of cereals revisited: ITS phylogeny reveals new species relationships. European Journal of Plant Pathology 109: 841-850.

Crous PW, Schumacher RK, Akulov A, et al. (2019a). New and Interesting Fungi. 2. Fungal Systematics and Evolution 3: 57-134.

Crous PW, Verkley GJM, Groenewald JZ, et al. (eds) (2019b). Fungal Biodiversity. Westerdijk Laboratory Manual Series 1: 1-425. Westerdijk Fungal Biodiversity Institute, Utrecht, The Netherlands.

Cunningham PC (1990). A serious attack by Spermospora avenae on oats - a disease new to Western Europe. Plant Pathology 39: 191196.

Dean R, Van Kan JA, Pretorius ZA, et al. (2012). The top 10 fungal pathogens in molecular plant pathology. Molecular Plant Pathology 13: 414-430.

Descals E, Marvanová L, Webster J (1998). New taxa and combinations of aquatic hyphomycetes. Canadian Journal of Botany 76: 1647-1659.

Doehlemann G, Okmen B, Zhu W, et al. (2017). Plant pathogenic fungi. Microbiology Spectrum 5: FUNK-0023-2016.

Fan XL, Bezerra JDP, Tian CM, et al. (2018). Families and genera of diaporthalean fungi associated with canker and dieback of tree hosts. Persoonia 40: 119-134.

Feng P, Klaassen CH, Meis JF, et al. (2013). Identification and typing of isolates of Cyphellophora and relatives by use of amplified fragment length polymorphism and rolling cycle amplification. Journal of Clinical Microbiology 51: 931-937.

Feng P, Lu Q, Najafzadeh MJ, et al. (2014). Cyphellophora and its relatives in Phialophora biodiversity and possible role in human infection. Fungal Diversity 65: 17-45.

Frank AB (1897). Ueber die Zerstörung der Gerste durch einen neuen Getreidepilz. Wochenschrift für Brauerei 14(42): 518-520.

Goodwin SB (2002). The barley scald pathogen Rhynchosporium secalis is closely related to the discomycetes Tapesia and Pyrenopeziza. Mycological Research 106: 645-654.

Gianoulis TA, Griffin MA, Spakowicz DJ, et al. (2014). Genomic analysis of the hydrocarbon-producing, cellulolytic, endophytic fungus Ascocoryne sarcoides. PLoS Genetics 8: e1002558.

Groenewald JZ, Nakashima C, Nishikawa J, et al. (2013). Species concepts in Cercospora: spotting the weeds among the roses. Studies in Mycology 75: 115-170.

Grudzinska-Sterno M, Yuen J, Stenlid J, et al. (2016). Fungal communities in organically grown winter wheat affected by plant organ and development stage. European Journal of Plant Pathology 146: 401417.

Hernández-Restrepo M, Madrid H, Tan YP, et al. (2018). Multi-locus phylogeny and taxonomy of Exserohilum. Persoonia 41: 71-108.

Hoog GS de, Guarro J, Gené J, et al. (2000). Atlas of clinical fungi. 2nd ed Utrecht/Reus: Centraalbureau voor Schimmelcultures/Universitat Rovira i Virgili.

Johnston PR, Seifert KA, Stone JK, et al. (2014). Recommendations on generic names competing for use in Leotiomycetes (Ascomycota). IMA Fungus 5: 91-120.

Karolewski Z, Fitt BD, Latunde-Dada AO, et al. (2006). Visual and PCR assessment of light leaf spot (Pyrenopeziza brassicae) on winter oilseed rape (Brassica napus) cultivars. Plant Pathology 55: 387-400. 
Katoh K, Standley DM (2013). MAFFT Multiple sequence alignment software version 7: improvements in performance and usability. Molecular Biology and Evolution 30: 772-780.

Kearse M, Moir R, Wilson A, et al. (2012). Geneious Basic: an integrated and extendable desktop software platform for the organization and analysis of sequence data. Bioinformatics 28: 1647-1649.

King KM, Eyres GJ, West JS, et al. (2020). Novel multiplex and loopmediated isothermal amplification (LAMP) assays for rapid species and mating-type identification of Oculimacula acuformis and $O$. yallundae (causal agents of cereal eyespot), and application for detection of ascospore dispersal and in planta use. Phytopathology https://doi.org/10.1094/PHYTO-04-20-0116-R

King KM, West JS, Brunner PC, et al. (2013). Evolutionary relationships between Rhynchosporium Iolii sp. nov. and other Rhynchosporium species on grasses. PLOS ONE 8: e72536.

Klaubauf S, Tharreau D, Fournier E, et al. (2014). Resolving the polyphyletic nature of Pyricularia (Pyriculariaceae). Studies in Mycology 79: 85-120.

Lee HK, Tewari JP, Turkington TK (2001). A PCR-based assay to detect Rhynchosporium secalis in barley seed. Plant Disease 85: 220-225.

Mäkelä K, Koponen H (1976). Telimenela ganreaena and Septogloeum oxysporum on grasses in Finland. Karstenia 15: 56-63.

Manamgoda DS, Cai L, McKenzie EHC, et al. (2012). A phylogenetic and taxonomic re-evaluation of the Bipolaris - Cochliobolus - Curvularia complex. Fungal Diversity 56: 131-144.

Manamgoda DS, Rossman AY, Castlebury LA, et al. (2014). The genus Bipolaris. Studies in Mycology 79: 221-288.

Marin-Felix Y, Hernández-Restrepo $\mathrm{M}$, Iturrieta-González I, et al. (2019a). Genera of phytopathogenic fungi: GOPHY 3. Studies in Mycology 94: 1-124.

Marin-Felix Y, Hernández-Restrepo M, Wingfield MJ, et al. (2019b). Genera of phytopathogenic fungi: GOPHY 2. Studies in Mycology 92: 47-133.

McKevith B (2004). Nutritional aspects of cereals. Nutrition Bulletin 29: 111-142.

Mohd-Assaad N, McDonald BA, Croll D (2019). The emergence of the multi-species NIP1 effector in Rhynchosporium was accompanied by high rates of gene duplications and losses. Environmental Microbiology 21: 2677-2695.

Nirenberg HI (1981). Differentiation of Pseudocercosporella strains causing foot rot disease of cereals. 1. Morphology. Zeitschrift für Pflanzenkrankheiten und Pflanzenschutz 88: 241-248.

Pärtel K, Baral H-O, Tamm H, et al. (2017). Evidence for the polyphyly of Encoelia and Encoelioideae with reconsideration of respective families in Leotiomycetes. Fungal Diversity 82: 183-219.

Penselin D, Münsterkötter M, Kirsten S, et al. (2016). Comparative genomics to explore phylogenetic relationship, cryptic sexual potential and host specificity of Rhynchosporium species on grasses. BMC Genomics 17: 953.

Quaedvlieg W, Verkley GJM, Shin H-D, et al. (2013). Sizing up Septoria. Studies in Mycology 75: 307-390.

Réblová M, Untereiner WA, Réblová K (2013). Novel evolutionary lineages revealed in the Chaetothyriales (fungi) based on multigene phylogenetic analyses and comparison of its secondary structure. PLoS One 8: e63547.

Ronquist F, Teslenko M, Van der Mark P, et al. (2012). MrBayes 3.2: Efficient Bayesian phylogenetic inference and model choice across a large model space. Systematic Biology 61: 539-542.

Seena S, Pascoal C, Marvanova L, et al. (2010). DNA barcoding of fungi: a case study using ITS sequences for identifying aquatic hyphomycete species. Fungal Diversity 44: 77-87.

Sprague R, Johnson AG (1936). A new Pseudodiscosia. Mycologia 28:
$181-185$

Stewart EL, Liu Z, Crous PW, et al. (1999). Phylogenetic relationships among some cercosporoid anamorphs of Mycosphaerella based on rDNA sequence analysis. Mycological Research 103: 1491-1499.

Stukenbrock EH, Quaedvlieg W, Javan-Nikhah M, et al. (2012). Zymoseptoria ardabiliae and Z. pseudotritici, two progenitor species of the septoria tritici leaf blotch fungus Z. tritici (synonym: Mycosphaerella graminicola). Mycologia 104: 1397-1407.

Sutton BC (1980). The Coelomycetes. Fungi Imperfecti with Pycnidia, Acervuli and Stromata. CMI, Kew.

Sutton BC, Pollack FG (1974). Microfungi on Cercocarpus. Mycopathologia 52: 331-351.

Turland NJ, Wiersema JH, Barrie FR, et al. (eds.) 2018: International Code of Nomenclature for algae, fungi, and plants (Shenzhen Code) adopted by the Nineteenth International Botanical Congress Shenzhen, China, July 2017. Regnum Vegetabile 159. Glashütten: Koeltz Botanical Books.

Videira SIR, Groenewald JZ, Braun U, et al. (2016). All that glitters is not Ramularia. Studies in Mycology 83: 49-163.

Vu D, Groenewald M, de Vries M, et al. (2019). Large-scale generation and analysis of filamentous fungal DNA barcodes boosts coverage for kingdom fungi and reveals thresholds for fungal species and higher taxon delimitation. Studies in Mycology 92: 135-154.

Walz A, de Hoog GS (1987). A new species of Cyphellophora. Antonie van Leeuwenhoek 53:143-146.

Zaffarano PL, McDonald BA, Linde CC (2008). Rapid speciation following recent host shifts in the plant pathogenic fungus Rhynchosporium. Evolution 62: 1418-1436.

Zaffarano PL, McDonald BA, Linde CC (2011). Two new species of Rhynchosporium. Mycologia 103: 195-202.

Zaveri A, Mann RC, Kaur JK, et al. (2020). Phylogenetic placement of Spermospora avenae, causal agent of red leather leaf disease of oats. Australasian Plant Pathology 49: 551-559.

Zhang Z, Schwartz S, Wagner L, et al. (2000). A greedy algorithm for aligning DNA sequences. Journal of Computational Biology 7: 203-214.

\section{Supplementary Material: http://fuse-journal.org/}

Fig. S1. Consensus phylogram (50\% majority rule) resulting from a Bayesian analysis of the ITS sequence alignment of sequences generated in this study and reference sequences from NCBI GenBank. Bayesian posterior probabilities $(\mathrm{PP})>0.85$ are shown at the nodes and thickened lines represent nodes with $P P=1.00$. The scale bar represents the expected changes per site. Species and culture collection numbers are indicated. The tree was rooted to Ascocoryne sarcoides (culture NRRL 50072).

Fig. S2. Consensus phylogram (50\% majority rule) resulting from a Bayesian analysis of the LSU sequence alignment of sequences generated in this study and reference sequences from NCBI GenBank. Bayesian posterior probabilities $(\mathrm{PP})>0.85$ are shown at the nodes and thickened lines represent nodes with $P P=1.00$. The scale bar represents the expected changes per site. Species and culture collection numbers are indicated. The tree was rooted to Ascocoryne sarcoides (culture NRRL 50072).

Fig. S3. Consensus phylogram (50\% majority rule) resulting from a Bayesian analysis of the act sequence alignment of sequences generated in this study and reference sequences from NCBI GenBank. Bayesian posterior probabilities (PP) $>0.85$ are shown at the nodes and thickened lines represent nodes with $P P=1.00$. The scale bar represents the expected changes per site. Species and culture collection numbers are indicated. The tree was rooted to Ascocoryne sarcoides (culture NRRL 50072). 
Fig. S4. Consensus phylogram (50\% majority rule) resulting from a Bayesian analysis of the rpb1 sequence alignment of sequences generated in this study and reference sequences from NCBI GenBank. Bayesian posterior probabilities (PP) $>0.85$ are shown at the nodes and thickened lines represent nodes with $P P=1.00$. The scale bar represents the expected changes per site. Species and culture collection numbers are indicated. The tree was rooted to Ascocoryne sarcoides (culture NRRL 50072).

Fig. S5. Consensus phylogram (50\% majority rule) resulting from a Bayesian analysis of the $r p b 2$ sequence alignment of sequences generated in this study and reference sequences from NCBI GenBank. Bayesian posterior probabilities (PP) $>0.85$ are shown at the nodes and thickened lines represent nodes with PP $=1.00$. The scale bar represents the expected changes per site. Species and culture collection numbers are indicated. The tree was rooted to Ascocoryne sarcoides (culture NRRL 50072).

Fig. S6. Consensus phylogram (50\% majority rule) resulting from a Bayesian analysis of the tef1 sequence alignment of sequences generated in this study and reference sequences from NCBI GenBank. Bayesian posterior probabilities (PP) $>0.85$ are shown at the nodes and thickened lines represent nodes with $P P=1.00$. The scale bar represents the expected changes per site. Species and culture collection numbers are indicated. The tree was rooted to Ascocoryne sarcoides (culture NRRL 50072).
Fig. S7. Consensus phylogram ( $50 \%$ majority rule) resulting from a Bayesian analysis of the full set 6-gene (ITS, LSU, act, tef1, rpb1, rpb2) sequence alignment. Bayesian posterior probabilities (PP) $>0.85$ are shown at the nodes and thickened lines represent nodes with PP = 1.00. The scale bar represents the expected changes per site. Species and culture collection numbers are indicated. The tree was rooted to Ascocoryne sarcoides (culture NRRL 50072).

Fig. S8. Consensus phylogram (50\% majority rule) resulting from a Bayesian analysis of the full set 4-gene (ITS, LSU, act, tef1) sequence alignment. Bayesian posterior probabilities (PP) $>0.85$ are shown at the nodes and thickened lines represent nodes with PP $=1.00$. The scale bar represents the expected changes per site. Species and culture collection numbers are indicated. The tree was rooted to Ascocoryne sarcoides (culture NRRL 50072).

Fig. S9. Consensus phylogram (50\% majority rule) resulting from a Bayesian analysis of the full set 2-gene $(r p b 1, r p b 2)$ sequence alignment. Bayesian posterior probabilities (PP) $>0.85$ are shown at the nodes and thickened lines represent nodes with PP $=1.00$. The scale bar represents the expected changes per site. Species and culture collection numbers are indicated. The tree was rooted to Ascocoryne sarcoides (culture NRRL 50072). 